\title{
El relieve histórico de M. Agrippa, los relieves de Pan Caliente y el Altar del Foro emeritense*
}

\author{
TRINIDAD Nogales BasarRate**
}

\begin{abstract}
RESUMEN
ABSTRACT

Un complejo proceso de investigación, dentro del que llevamos sobre el Foro emeritense ${ }^{1}$, nos permitió hace unos años identificar un nuevo monumento,

un altar, tal vez el Ara Providentiae

Within the Emeritean Forum Research Program a complex research process allowed us a few years ago to identify a new monument: an altar, perhaps the Ara Providentiae which can be seen in
\end{abstract}

* En el número anterior, Espacio. Tiempo y Forma, Serie II, 12, 1999, se publicó el artículo del Dr. Poveda “Reinterpretación del relieve histórico emeritense de M. Agrippa a partir de un nuevo fragmento". En dicho artículo las conclusiones son bastante similares, salvando numerosas cuestiones de planteamiento divergentes, a las que hemos venido exponiendo y editando desde hace varios años en relación al posible Altar del Foro emeritense. Como en buena medida las creiamos conocidas por el autor, ya que las cita parcialmente, pero no fueron aludidas y explicitadas en su texto, sirvan estas líneas de revisión, aclaración y complemento a una "reinterpretación" existente y editada. Nuestra interpretación no se limita a la incorporación de un nuevo fragmento sino que comprende todo el conjunto de Pancaliente y lo interrelaciona con la decoración interna y externa del Altar. Cfr. en nota la bibliografia al respecto, en extenso recogida en: $T$. Nogales Basarrate, “Un altar en el Foro de Augusta Emerita", en P. LEÓN y T. NogALES, Actas de la III Reunión sobre escultura romana en Hispania (Córdoba, 1997). Madrid, 2000, págs. 25-46.

** M.N.A.R. Departamento de Investigación.

Este programa de Investigación debe agradecer a numerosas personas e instituciones la ayuda prestada: En primer lugar deseamos destacar la participación de la Obra Social de Caja Duero, entidad que nos brindó su apoyo en sendos proyectos de investigación sobre este espacio, gracias a los cuales hemos podido incluir el excelente trabajo D. José manuel Jerez Linde, autor de los dibujos presentados y miembros del equipo en el M.N.A.R. El Instituto Arqueológico Alemán de Berlín y Madrid, en las personas de los Dres. Trillmich y Uibert, quienes nos procuraron varias becas de investigación en la sede berlinesa, y de cuya amistad nos honramos. El prof. Dr. Fishwick, de la Universidad de Alberta, quien amablemente leyó mi anterior manuscrito, y de cuyo magisterio nos beneficiamos con sus observaciones siempre importantes. Finalmente, de modo genérico, quiero expresar mi gratitud a mis colegas de M.N.A.R., gracias a cuya colaboración y generosidad en mis constantes molestias han hecho más fácil la tarea. 
reflejada en las acuñaciones monetales de la Colonia.

El análisis se inicia en 1987 cuando relacionamos un fragmento inédito de los almacenes del M.N.A.R., relieve con parte de un toro engalanado para

el sacrificio, como integrante del

Relieve histórico de M. Agrippa, a pesar de la distinta procedencia de ambos.

El estudio que hemos propuesto es una interpretación del conjunto, tanto

del relieve donde iría la escena de Agrippa como de buena parte del resto de Pan Caliente, hasta ahora sin conectar entre sí, $y$ el resultado de este análisis global es la identificación de este grupo como la decoración interna y externa del Altar, y ello nos permitió una restitución completa del monumento.

Además, planteamos la posible ubicación del Altar y la relación del taller escultórico de éste con el que trabajó en la monumentalización del singular espacio del Foro emeritense. the coins minted at the Colony. Anaylisis of different parts of the project started in 1987 when an unpublished fragment from the National Museum of Roman Art at Merida's reserve collection was related with the part of one with a bull festoned for its sacrifice, thus being considered as a part of the historical relief of $M$. Agrippa, in spite of the different provencience of both fragments. The study is an interpretation not only of the relief enssemble where the Agrippa scene should be, as well as the most part of the Pan Caliente one, till now unrelated. The result of this global anaylisis is this group's identification as well as the altar's internal and external decoration, which has allowed for a complete restitution of the monument.Besides this a possible emplacement for the Altar is suggested as well as are the relations existing between the altar's workshop with the one that worked on the monumentalization of the singular space of the Emeritean Forum.

\section{EL ORIGEN DE UNA HIPÓTESIS}

Los materiales procedentes de Pan Caliente ${ }^{2}$ han suscitado siempre gran interés en la comunidad científica dada su calidad y variedad tipológica. Las circunstancias adversas de su hallazgo y posterior documentación motivaron que, desde el momento de su recuperación, los datos oscilaran y al ser ingresados en el Museo por Álvarez Saénz de Buruaga, en 1943, el cómputo total de los fragmentos hubiera aumentado en varias

2 En 1934 en una zona periférica de la población, recogida en la toponimia ya como Pan Caliente o Pancaliente, a orillas del Guadiana, se recuperaron una serie de fragmentos marmóreos al realizar la cimentación de una casa. El responsable de la intervención arqueológica, a la sazón, fue el primer editor de los mismos: A. FLORIANO, “Excavaciones en Mérida (campañas de 1934 y 1936)", ArchEspA 55, 1944, págs. 151-192. Clasifica 27 fragmentos en seis grupos. 
obras $^{3}$. Este hecho, no obstante, apenas fue remarcado en los distintos trabajos que analizaron los relieves y su contexto, pasando desapercibido y siendo, sin embargo, de interés para explicar la conexión de los materiales atribuidos al grupo, como explicaremos más adelante.

Las obras fueron sucesivamente tratadas en estudios de conjunto, especialmente en el esencial corpus de García y Bellido ${ }^{4}$, quien puso en relación los relieves y cita el Ara Pacis como modelo inspirador de una parte de éstos ${ }^{5}$. Las piezas, muchas veces aisladamente, siguieron incorporándose a distintos estudios ${ }^{6}$, destacando la especial atención que la escena de sacrificio despertó entre los investigadores ${ }^{7}$.

Floriani Squarciapino, en su análisis pormenorizado de la plástica emeritense, fue determinante a la hora de definir los grupos escultóricos de Pan Caliente ${ }^{8}$, poniendo el dedo en la llaga de los posibles modelos inspiradores de los materiales emeritenses, focalizando éstos en los talleres metropolitanos de corte aúlico del Foro de Augusto ${ }^{9}$.

Pero el trabajo que mejor, y de modo más certero, interpretó los relieves en torno a la escena de sacrificio fué el de Trillmich $^{10}$, cuyo valor estribaba no sólo en conceder una cronología precisa al conjunto, sino en identificar la escena de sacrificio con un pasaje histórico-narrativo en el que Agrippa" es el protagonista central del sacrificio y primer retrato colonial del yerno del emperador y patrono de la Colonia, cuyo relevante rol en

3 J. Álvarez Saenz de Buruaga, "Museo Arqueológico de Mérida. Memoria". MMAP 1943, pág. 46, láms. $\vee$ a IX. Recuenta en total 39 piezas. Hay que poner de relieve que desde 1934 , fecha de aparición, hasta 1943 en que se ingresan en el Museo, no habia registro sistemático de los fondos emeritenses, por lo que es fácil que se hubieran producido nuevas incorporaciones al lote inicial.

${ }^{4}$ A. Garcia y Bellido, Esculturas romanas de España y Portugal. Madrid, 1949, págs. 402, 415-420, láms. 284, 297-301.

5 lbid, pág. 416-419.

6 H. SiCHTERMANN, "Archäologische Funde und Forschungen in Spanien von 1940 bis 1953", AA 1954, págs. 313-451

P. VEYNE, "Ordo et populus, génies et chefs de file», Mefra LXXIII, 1961, pág. 239; D. FISHWICK, The Imperial Cult in the Latin West. II, 1. Leiden, 1991, pág. 503, lám. XC a. (en adelante ICLW.

8 M. Flomiani Squarciapino, "Ipotesi di lavoro sul gruppo di sculture di Pan Caliente", Augusta Emerita Actas del Simposio internacional conmemorativo del Bimilenario de Mérida. Madrid, 1975, págs. 55-62; Ead., "Cultura artistica di Mérida romana", Homenaje a J. Álvarez Sáenz de Buruaga. Madrid, 1982, págs. 40-42, fig. 7-8.

9 Ibid. Nota supra.

10 W. Trillmich, "Ein historisches Relief in Mérida mit Darstellung des M. Agrippa beim Opfer», MM27, 1986, págs. 279-304, láms. 39-49.

J. M. Roddaz, Marcus Agrippa. Rome, 1984; Id., "Agripa y la península Ibérica", Anas 6, 1995. págs. 111-126; I. Romeo, Ingenuus Deo. Limmagine di Agrippa. Roma, 1998, págs. 137 138, 195-197, figs. 194-196. 
Emerita refleja la epigrafía local ${ }^{12}$. La relación de la escena con el culto imperial, evidenciaba nuevas opciones iconográficas del relieve ${ }^{13}$.

En 1987, tras la vorágine de la inauguración del Museo Nacional de Arte Romano, apenas unos meses después de publicar Trillmich su artículo, volvimos a encontrarnos durante el proceso de revisión, documentación y control de los materiales de reserva, un fragmento relivario que ya habia llamado años antes nuestra atención en los antiguos almacenes del Museo (fig. 1)

El fragmento poseía una representación parcial de un tronco de un animal, presumiblemente un toro por la tipología anatómica, que portaba la clásica banda o dorsuale típico en los animales preparados para el sacrificio $^{14}$. Dada la iconografía del animal y, sobre todo, las concomitancias técnico-estilísticas que presentaba aquel fragmento con el citado conjunto del relieve de Agrippa, lo referimos a su editor, el Dr. Trillmich, quién también había reparado en esta pieza, pero la había desechado por considerarla de mayor escala al resto del grupo de Pan Caliente y, lógicamente, por ser su procedencia documentada distinta al grupo citado.

Desde el punto de vista iconográfico el nuevo fragmento con el toro engalanado casaba a la perfección con la escena central del relieve de Agrippa, como referiremos más adelante.

Analizando los detalles técnicos, particularmente la tipología de los mármoles ${ }^{15}$, elaboración trasera de los relieves y el grosor de las placas, se percibía un trabajo de similares caracteres, muy cercano en sus detalles de manufactura. El tipo de relieve, de carácter pictórico y de cuidada factura, remitía al resto del conjunto (fig. 2).

12 L. Garcia Iglesias, Epigrafia romana de Augusta Emerita. Madrid, 1972. (tesis doctoral inédita)

13 D. FISHWICK, ICLW, op. cit., pág. 503, lám. XC a

$14 \quad{ }^{\circ}{ }^{\circ}$ Inventario 23. 180. Ingresa el 2 de Diciembre de 1975 en la colección permanente del M. N. A. R.

J. de Alarcao y A. Tavares, "A Roman Marble Quarry in Portugal», Studia Pompeiana and Classica in Honor of W. F. Jashemski. Volume 11:Classica. New York, 1989; T. Nogales Basarrate, El retrato privado emeritense. Badajoz, 1997. Cfr. capítulo de materiales y técnicas de trabajo, págs. 171-204, con bibliografia precedente; Nogales-Lapuente-Barkera, "Marbles and other stones used in Augusta Emerita", IV ASMOSIA. Bordeaux, 1997; F. S. Real, "Rochas e minerais. A mineraçao romana: exploração de materiais não metálicos", en A. MouTiNHO ET ALII. Portugal Romano. A exploração dos Recursos naturais. Lisboa, 1997, pág. 77 y ss.; P. PEnSAbene (ed.), Marmi Antichi II. Cave e tecnica di lavorazione, provenienze e distribuzione. Roma, 1998. Cfr. los distintos mapas de distribución de canteras peninsulares en las que se incluyen las locales de la zona y se recoge bibliografía; T. Nogales Basarrate, "La escultura del territorio emeritense. Reflejos de la economia y producción en Lusitania Romana", en J. G. Gorges y F. G. RODRIgUez MARtin (eds. ), Économie et territoire en Lusitanie romaine. Madrid, 1999, págs. 483-497. 


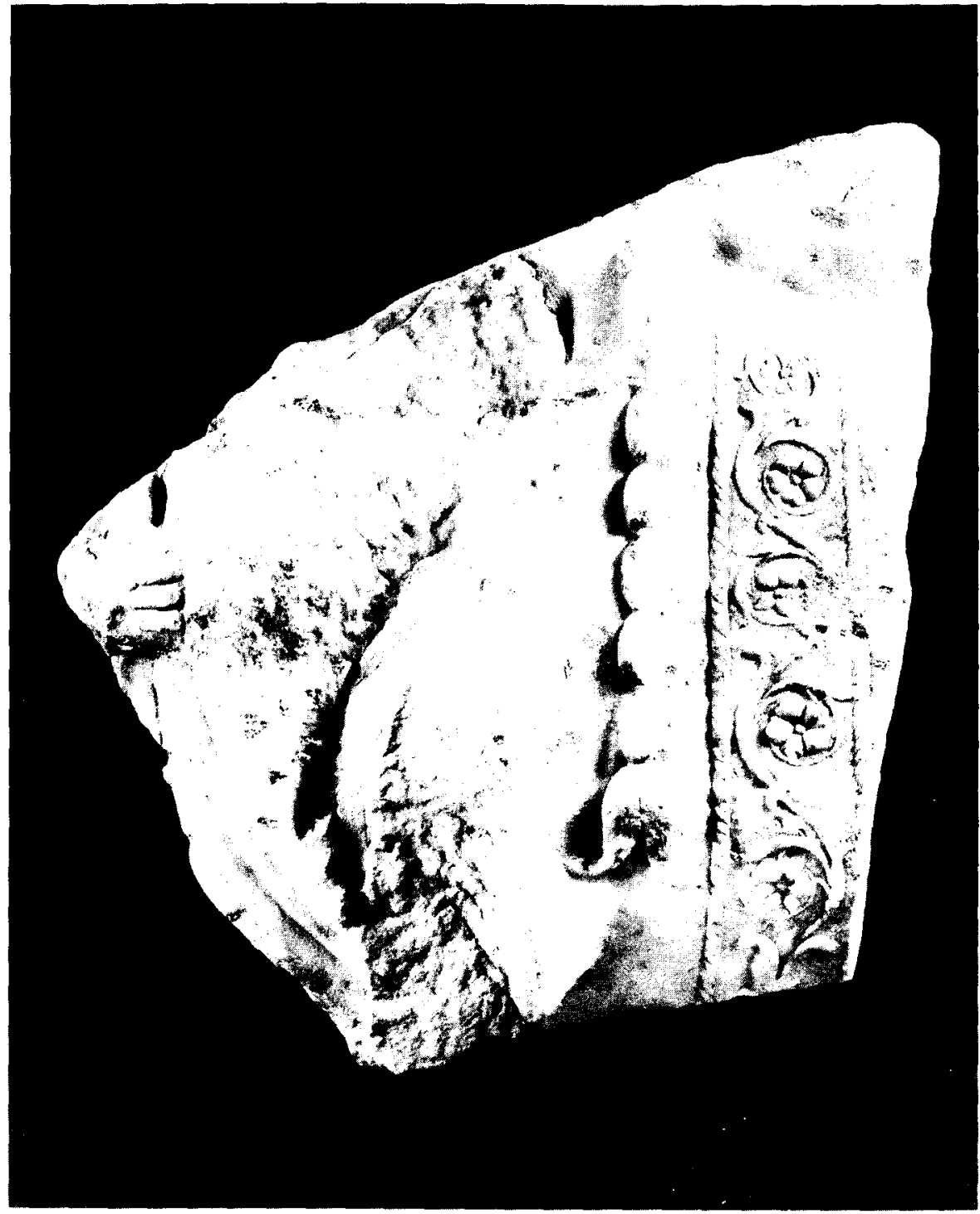

Fig. 1. Fragmento-relieve con toro. Foto D.A.I.R. Patterson, R 123-96-4. 

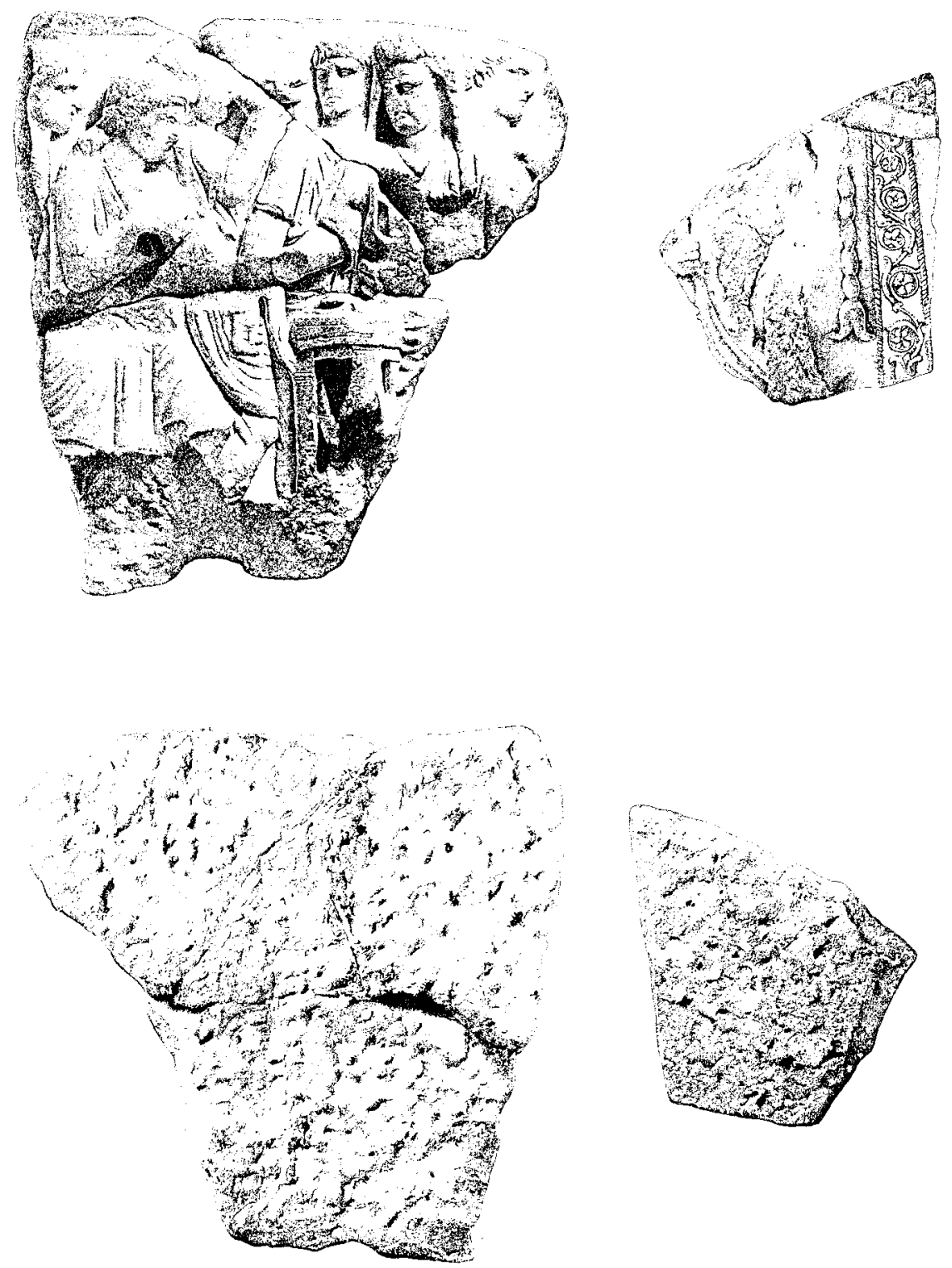

Fig. 2. Dibujos del relieve de Agrippa, escena de sacrificio, y del relieve del toro, anverso y reverso. Autor: J. M. Jerez Linde. 
Así las cosas, comenzamos a trabajar en la documentación de los fondos para esclarecer el origen de la nueva obra, y basta leer la cédula de inventario donde como toda información se cita textualmente "Teatro", como lugar de origen ${ }^{16}$. La diversa procedencia de los relieves alejaba la posibilidad de conectarlos entre sí.

Cuando releímos con atención las primeras publicaciones, las de Floriano y Saénz de Buruaga ${ }^{17}$, observamos la disparidad numérica a la hora de hacer el recuento de los fragmentos. En primer lugar, los materiales hallados en 1934, se depositaron en los almacenes del teatro, hasta su ingreso en la colección permanente del Museo en 1943, año en que Álvarez Sáenz de Buruaga accede a la dirección del Centro y acomete la imprescindible tarea de registrar y controlar unos fondos dispersos en distintos espacios arqueológicos de la ciudad. Del primer recuento de Floriano, con veintisiete fragmentos, hasta el ingreso de treinta y nueve de Saénz de Buruaga habian transcurrido más de nueve años. Nueve largos años, con una guerra civil de por medio, y con un control del patrimonio descentralizado: por un lado materiales recogidos en el Museo Arqueológico emeritense, por otro colecciones y fondos sin apenas documentarse dispersos en solares y espacios muy diversos. Entre los lugares de almacenamiento cabe señalar el "almacén del teatro" como lugar de mayor concentración de fondos, a juzgar por la ingente cantidad de obras en cuya cédula se ha registrado esta procedencia. Cuando los responsables del Museo se apremian a documentar los fondos dispersos no poseen otra información que la que registran, la topografía de las obras: el almacén del teatro.

Ante esta tesitura, consideramos que el fragmento con el toro, del que además se había perdido un extremo, a juzgar por las dimensiones recogidas en la cédula, podía proceder de aquellos fondos almacenados en el teatro y descontextualizados. Tal vez en la progresiva manipulación de las obras de Pan Caliente, en el posible hallazgo en los años de la guerra de nuevos fragmentos en la zona, en la división de elementos considerados del mismo bloque, o en otros avatares, pudiéramos hallar la explicación a la descontextualización de este fragmento del resto, que a nuestro juicio era claramente parte del relieve de sacrificio, no por origen sino por las concomitancias técnicas e iconográficas que hemos referido (figura 2).

16 No entendemos la afirmación que refiere A. POVEDA, art. cit., pág. 391 «el nuevo fragmento que hemos identificado apareció en la misma área de Mérida que los otros restos marmóreos del mismo relieve histórico, es decir en la zona de Pancaliente". La necesaria consulta de la cédula de inventario es concluyente.

Art. cit. supra notas 1 y 2. 
Los años ulteriores al descubrimiento los centramos en la documentación de la pieza, toda vez que ya en algunas conferencias y publicaciones apuntamos tímidamente la nueva hipótesis. En el Congreso Internacional de Tarragona, con motivo de la exposición La ciudad hispanorromana, al analizar los fragmentos de Pan Caliente ${ }^{18}$ esbozamos algunas hipótesis en torno al conjunto del relieve de Agrippa, sin aún definir la nueva interpretación por estar en curso. La conexión del fragmento con el relieve histórico y de todo el grupo con un altar monumental, como apuntamos en la edición del catálogo de la muestra La mirada de Roma ${ }^{19}$, cobraba su fuerza y siguió su curso ${ }^{20}$.

De igual modo, en la muestra internacional Hispania romana al efectuar la ficha del conjunto de Pan Caliente citamos la existencia del fragmento de un toro e identificamos los relieves con un altar monumental del tipo al de las acuñaciones monetales: "En nuestro reciente análisis, en el que se incorpora al grupo un fragmento con un toro de sacrificio, se introduce una nueva hipótesis interpretativa: que todo este conjunto provenga del área del Foro Municipal, como parte de una edificación conmemorativa, posiblemente un altar monumental del tipo al representado en las monedas tiberianas emeritenses" ${ }^{21}$, y en la bibliografía adjunta se refería la existencia de los trabajos en curso. La «interpretación», pues, estaba ya esbozada y planteada.

Nuestro programa de investigación continuó su proceso, pero ello no nos impidió hacer públicas nuestras hipótesis al respecto, efectuando así diversas conferencias y seminarios en los que incluímos el estudio del altar como nuevo planteamiento ${ }^{22}$.

Dado el interés del tema procedimos en 1997 a presentarlo a la III Reunión de Escultura Romana en Hispania. El trabajo, ya pomenorizado, se incluyó en las Actas de dicha Reunión. Lamentablemente, por razones

18 Ead. «Relieve de Agripa sacrificador, de Mérida", pág. 290, y J. M. Ál.varez Martinez, "Ciudades romanas de Extremadura", págs. 139 y 153, ambos en Varios, La ciudad hispanorromana. Madrid, 1993.

19 T. Nogales, "Relieve de una escena de sacrificio con la representación de M. Agripa", en Varios, La Mirada de Roma. Retratos romanos de los museos de Mérida, Toulouse y Tarragona. Barcelona, 1995, pág. 206.

20 En este sentido, como apunta Poveda en su articulo, durante la celebración del mencionado Curso de Verano de la UNED en Mérida, en 1996, "Poder e imagen en Roma», al presentar el relieve de Agrippa dentro de las intervenciones, procedimos a dar a conocer la obra y mencionar nuestras ideas al respecto.

21 Ead., "Relieve de Agripa", en J. ARCE y otros, Hispania romana. Desde tierra de conquista a provincia del Imperio. Roma, 1997, pág. 354.

22 Valgan como ejemplo las sucesivas conferencias al respecto pronunciadas en el Museo Arqueológico Nacional de Madrid, el Instituto Arqueológico Alemán de Berlin y la Universidad Rovira i Virgili de Tarragona. 
que no vienen al caso, la publicación vio demorar desde 1997 su salida hasta el pasado ejercicio ${ }^{23}$.

En 1998, con motivo de la Muestra Hispania el legado de Roma, en el año de Trajano, además de elaborar la documentación informativa al respecto para el catálogo y paneles ${ }^{24}$ se nos solicitó por parte de los comisarios la presentación pública y recreación plástica de dicho monumento, labor que llevamos a efecto con el concurso de los arquitectos responsables del montaje expositivo ${ }^{25}$, y presentándose como aportación científica a dicho evento. Los numerosos visitantes de la muestra tuvieron ocasión de conocer en detalle el Altar del foro emeritense, como un ejemplo más

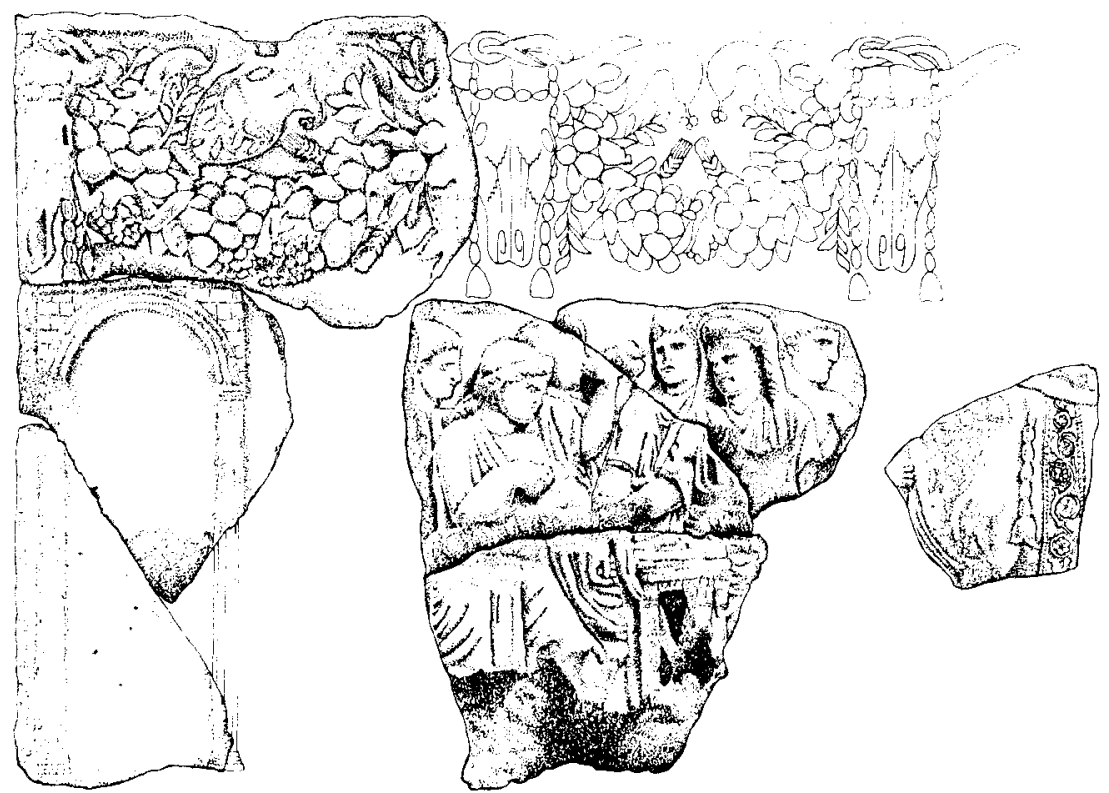

Fig. 3. Dibujo hipótesis de reconstrucción de la escena de suovetaurile, que sería uno de los frentes laterales del altar. Autor: J. M. jerez Linde, según T. Nogales.

23 T. Nogales BasarRate, "Un altar en el foro de Augusta Emerita", en P. LEÓn y T. Nogales (eds. ). Actas de la III Reunión sobre escultura romana en Hispania. (Córdoba, 1997)". Madrid, 2000 , págs. $25-46$.

${ }_{24}$ Ead., "Relieves del Ara Providentiae ", en M. Almagro-Gorbea y J. M. Álvarez Martinez, Hispania el legado de Roma. En el año de Trajano. Madrid, 1998, pág. 532. En la bibliografia se cita el artículo precedente.

25. En este sentido, agradecemos la colaboración de J. I. Macua y P. Garcia Ramos, autores del montaje expositivo, quienes propiciaron que su equipo llevara a la práctica la recreación del altar. 
de la siempre necesaria colaboración de los programas científicos en los proyectos de difusión de nuestras novedades patrimoniales.

\section{EL FRAGMENTO DEL RELIEVE CON EL TORO Y LA NUEVA LECTURA ESCÉNICA}

Ya hemos explicado en líneas precedentes que las cuestiones documentales en relación a la posible procedencia del fragmento del toro, por un lado, y los aspectos técnico- formales en el tratamiento de las lastras marmóreas, tanto en el tipo de material como en el sistema de trabajo de la zona trasera de las piezas, venían a reforzar la posible relación del nuevo fragmento con el llamado relieve histórico de Agrippa $^{26}$ (fig. 3).

Si pasamos a la descripción del fragmento ${ }^{27}$ apreciamos la parte anterior del cuerpo de un toro o buey, en medio-bajo relieve, en el momento que está siendo conducido por un personaje masculino del que se consevan cuatro dedos de la mano izquierda, que asen las riendas de sujección del animal, el denominado capistrum ${ }^{28}$. Aunque lo lógico es pensar que los animales que son conducidos deben ir asegurados en su marcha, a veces van sueltos ${ }^{23}$. Si no se aprecia la soga del capistrum en el cuello del animal, la posición de la mano del victimarius con los dedos doblados en actitud de asir algo hace sospechar que los pliegues del cuello del toro estén ocultando las riendas (fig. 1).

El toro posee una gran corpulencia, y a pesar de apreciar sólo en parte su tronco, ni cabeza ni patas, deducimos que su postura sería sesgada con respecto al punto de observación del espectador, en primer plano.

Si la zona del cuello, bolsas de la papada, oreja izquierda y arranque de la pata anterior izquierda tienen un gran deterioro, el resto del tronco está mejor conservado.

26 T. Nogales Basarrate, art. cit. supra, págs. 28-29.

2? Ead., art. cit. supra. Seguimos los mismos textos del citado trabajo.

28 En la columna de Trajano se ven este tipo de correajes, usados por el victimarius en los animales de sacrificio: I. Scott Ryberg, Rites of the State Religion in Roman Art. Mem. Am. Ac. Rom. XXII. lám. XLIV, fig. 67; K. D. WHITE, Farm Equipment of the Roman World. Cambridge, 1975, págs. $94-95$, fig. 6 a.

${ }_{29}$ En algunos relieves de sacrificio el victimarius simplemente acompaña y controla de cerca al animal para evitar que se espante en plena procesión. Cfr.: I. ScOTT RyBERG, op. cit., lám. XVI. fig. 30 y 32, ambos altares de pequeño formato, el altar del Vicus Aulesti y el altar de la Colección Chigi, en los que la escena se sintetiza simbólicamente. Otro caso bien claro son los Anaglypha Traiani, donde los tes animales de la suovetaurilia van sueltos, vid.: M. TORELLI, Typology and Structure of Roman Historical Reliefs. Michigan, 1982., lám. IV. 3 y IV. 4. 
Lo más singular iconográficamente es que el toro va adornado con $v_{i t t a}^{30}$ y dorsuale ${ }^{31}$, lo que evidencia su preparación al sacrificio ${ }^{32}$. La vitta está formada por siete ovas que rematan en un motivo floral campaniforme, el mismo que aparece en el extremo inferior del dorsuale. Aunque no es regla ni norma fija, la vitta suele estar colocada enlazando ambos cuernos y cae a los lados de las orejas; así la vemos en relieves tan singulares como el Altar de Domitius ${ }^{33}$, el Ara Pietatis ${ }^{34}$ o las souvetaurilia de los Anaglypha Traiani ${ }^{35}$. Teniendo en cuenta la disposición de la vitta en el relieve, muy cerca del dorsuale, es posible determinar que la posición de la cabeza del animal era frontal, girada con respecto a la postura de perfil de su cuerpo, por lo que se verían ambos extremos de la vitta, tal como se aprecia en el fragmento de la decoración relivaria del Templum Gentis Flaviae $^{36}$.

La longitud de la vitta no sigue una regla fija, pues oscila sensiblemente desde aquéllas que apenas llegan al arranque del cuello, como se ve en las que penden en los relieves de la Cancelleria ${ }^{37}$, hasta las largas vittae que llevan los animales en el Ara Pietatis ${ }^{38}$ que caen hasta las patas. La morfología de las vittae varia según el carácter decorativo del relieve, siempre en consonancia con el estilo general del mismo. En el relieve emeritense la vitta que adorna al toro es lisa, mientras que las que llevan los bucráneos superiores del mismo relieve son gallonadas, iguales a las del Ara Pietatis ${ }^{39}$.

El dorsuale está decorado con gran detalle; los bordes van sogueados y la banda central lleva un roléo en el que unos finos tallos están engarzando flores penta, exa y octopétalas. El tipo de dorsuale es relativamente común, el emeritense es bastante parecido al que adorna al toro del

\footnotetext{
so El tipo de adorno se constata ya en vasos griegos desde el siglo VI a. C., cfr.: A. KRUG, Binden in der Griechischen Kunst. Hösel, 1968, págs. 37-41, lám. III. tipo 11. Sobre su evolución en época romana, vid:: M. NAGY, "Vitta, licium, taenia-gammadion. Beiträge zur Interpretation des Gammadions und zur Geschichte seiner Entstehung», CommunicAH 1988, págs. 81-91.

31 R. MOWAT, s. v. «Dorsuale», Darembeg-Saglio, Dictionnaire des antiquités grecques et romaines. Paris, 1892. 11. 1.

1. Scott Ryberg, op. cit.

Cir. M. Torelli, op. cit., lám. I. 4c.

RYBERG, op. cit., lám. XXI bis, fig. 36 c; M. TORELLI, op. cit., lảm. III. 20.

M. TORELLI, op. cit., lám. IV. 3 y 4.

R. PARIS (ed. ), Dono Hartwig: Originali ricongiunti e copie tra Ann Arbor e Roma. Ipotesi per il Templum Gentis Flaviae. Rome, 1994; E. GAZOA-A. E. HAECKL-R. PARIS, Images of Empire. Flavian fragments in Rome and Ann Arbor Rejoined. 1996, pág. 29, fig. 30.

37 RYBERG, op. cit., lám. XXIII.

38 Cfr: RYBerg, op. cit., lám. XXI, fig. 36; G. M. KOEPPEL, “Die historischen Reliets der römischen Kaiserzeit", Bjb 183, 1983, págs. 61-114. kat. 13, fig. 16.

39 Cfr. nota supra.
} 
relieve de Rávena ${ }^{40}$, del relieve del Louvre ${ }^{41}$ o de los Anaglypha Traianit2, en todos ellos el roléo ocupa el espacio central de la banda al completo. El roléo emeritense, por su sentido pictórico y por la disposición de los elementos que lo forman es más próximo al del relieve de Rávena ${ }^{43}$. Salvando las dimensiones y la distinta finalidad de las obras, el roléo emeritense encuentra sus paralelos más cercanos en algunos elementos de arquitectura decorativa, como las pilastras de la basílica Aemilia ${ }^{44}$ o los que se ven en el Ara Pacis ${ }^{45}$, o modelos menos representativos, pero elocuentes reflejos de la difusión de los esquemas de cada período, como el del friso de Fossombrone ${ }^{46}$, de fecha augustea ${ }^{47}$.

No sabemos, pues está fracturado en esa zona, como remataría este dorsuale emeritense, pero es de imaginar que su final seria recto.

Ya Trillmich en su artículo mencionó la existencia de animal para el sacrificio, puesto que se observa la imagen del victimarius ${ }^{48}$, detrás de la de Agrippa. No se trataria, pues de ninguna novedad ${ }^{49}$ asegurar la presencia de un toro, ya que este animal es el que suele-entre otros-formar parte de las escenas de actos de este género. ¿Qué escena sería la que se desarrollaría a derecha del victimarius?

La aparición del toro engalanado para el sacrificio forma parte de las denominadas hostiae incruentae, precedentes del sacrificio, las hostiae cruentae. Después de la probatio las victímas eran preparadas, adornadas con verbenae, infulae y dorsualia, para ser luego llevadas al altar. El repertorio escénico es bastante fijo en los personajes, con un deseo narrati$v^{50}$ y asociado al culto imperial ${ }^{51}$.

40 Vid. RYBERG, op. cit., lám. XXVIII, fig. 42 a; A. BonAnno, Portraits and other heads of Roman Historical Reliefs up to the Age of Septimius Severus. B. A. R. suppl ser. 6. Oxford, 1976, págs. 41-44, lám. 97.

41 A. Bonnano, op. cit., pág. 45 y ss., lám. 100.

Vid. TORELLi, op. cit., lám. IV 3 y 4.

Cfr. nota supra.

M. WEGNER, “Bauschmuck der Basilika Aemilia am Forum Romanum», $R M$ 94, 1987, págs. 325-329, lám. 142. 1 y 2

45 E. SIMON, op. cit., lám. 6.

4h G. Schönner, Römische Rankenfriese. Mainz am Rhein, 1995, pág. 36, cat. 90, lám. 27.2.

47 H. VON HESBERG, “Elemente der frühkaiserzeitlichen Aedikularchitektur», ÖJh 53, 1981. 1982, págs. 43-86., fig. 43.

48 W. TrillmiCH, art cit., 292, nota 28.

49 A. Poveda, art. Cit., pág. 390.

50 M. TORELLI, op. cit., págs. 5 y ss.

51 RyBerg, op. cit. ; H. VON HESBERG, "Archäologische Denkmäler zum römischen Kaiserkult», ANRW II. 16. 2, págs. 911-995; FISHWICK, ICLW II, 1, págs. 525, ss; S. TORTORELLA, "I rilievi del Louvre con suovetaurile: un documento del culto imperiale", Ostraka (, 1992, págs. 81-104. 
De derecha a izquierda el pasaje lo compondrían el toro y una sucesión de personajes relacionados con este acto ${ }^{52}$. Animales precedidos cada uno por el victimarius cuyo perfil se asoma detrás de Agrippa $^{53}$ en el primer caso. Tanto el tamaño de la mano como la posición de ésta en altura hacen posible la unión de ambos fragmentos.

El victimarius, en lo que se aprecia, lleva el torso desnudo, vestiria sólo el limus ${ }^{54}$. El toro es de gran tamaño ${ }^{55}$ ya que se sitúa en un primer plano, como la figura de Agrippa, mientras el victimarius discretamente se posiciona en este segundo nivel. El relieve emeritense ha cuidado con esmero las proporciones y los planos relivarios, hecho que no siempre se respeta en estas formas figurativas donde los animales no guardan mucha relación con el entorno circundante y adquieren una dimensión más simbólica que real ${ }^{56}$. El taller emeritense ha sabido captar este sentido pictórico que envuelve la plástica augustea y que va a mantenerse con fuerza en el relieve histórico ${ }^{57}$.

El centro del relieve lo ocupa la imagen de Agrippa, como ya advirtió Trillmich ${ }^{58}$, quien se dirige hacia uno de los camilli que está abriendo la acerra ante el foculus. En un segundo plano compositivo hay otro camillus, un tibicen y un tercer personaje de perfil.

La aparición del toro debe enmarcarse en un sacrificium, probablemente en las suovitaurilia ${ }^{59}$, con lo que la escena se podría alargar más a la derecha con la oveja y el cerdo que estarían conducidos también por sus respectivos victimarii, tal como se observa en buen número de escenas relivarias de estos sacrificios ${ }^{60}$. De incorporarse los tres animales al cortejo procesional, la escena cambiaría de dimensión y, en consecuencia, creemos que debe renovarse la lectura de este relieve.

\footnotetext{
TRILLMICH, art. cit, págs. 299 y ss.
}

TRILLMICH, art. cit., lám. 44-46 c, fig. 3.

5.4 El limus es la indumentaria más común de los victimarii, aunque también pueden ataviarse de otros modos, Cfr. RYBE.RG, op. cit., figs. 54 a-b. En el relieve del Louvre visten la toga.

sh En su dia, comentamos con $W$. Trillmich la posibilidad de que este toro fuera del relieve, pero a ambos nos parecia demasiado grande el tamaño. Una vez que se estudian la sucesión de planos en este tipo relivario, se aclaran las distintas escalas de los representados.

56 Es curioso el ejemplo de los relieves del arco de Susa, donde los toros tienen una proporción grotesca, vid: Ryberg, op. cit. ; J. PRIEUR, "Les arcs monumentaux dans les Alpes occidentales: Aoste, Suse, Aix-les-Bains", ANRW II, 12. 1, págs. 455 y ss, láms. VI, VII, VIII y IX.

57 G. KOEPPEL, "The Role of Pictorical Models in the Creation of the Historical Relief during the Age of Augustus», The Age of Augustus. Providence, Rhode Island, 1982.

58 TrILlMICH, art. cit., fig. 2-3.

59 I. RYBERG, op. cit., págs. 104-119; M. J. Vermaseren, «The suovetaurilia in Roman Art», BABesch 32, 1957, págs. 1-12; U. W. SCHULz, "Suovitaurilia und Solitaurilia", Philologus 117, 1973, págs. 3, ss; S. TORTORELLA, art. cit., passim.

60 M. TORELLI, op. cit., passim. 
En el dibujo-restitución Trillmich remataba ambos extremos con los perfiles de las arquitecturas, que sirven de espléndido marco compositivo para localizar las escenas, siendo además estas arquitecturas un buen vehículo de posible reconocimiento de algunos edificios ${ }^{61}$ en el presente. Si la escena del sacrificium prosigue en el tramo derecho a partir de donde se representa a Agrippa, como es más lógico, la longitud del relieve se incrementaría de un modo importante, por lo que se rompería el equilibrio formal del relieve rectangular y sobrepasaría la dimensión plausible ${ }^{62}$.

La reconstrucción de Poveda, que utiliza como base el dibujo de Stadler según Trillmich, tiene varios puntos de objeción. En primer lugar el pie de foto "Nueva propuesta de reconstrucción a partir de los fragmentos que hasta ahora se conocen" no se ajusta a los datos contrastados, ya que se conocen muchos más fragmentos relacionados con el relieve de Agrippa ${ }^{63}$. El autor superpone, además, en el friso superior del dibujo-composición informatizada un fragmento ${ }^{64}$ que por su remate en la arista izquierda pertenece a una zona angular del friso, nunca se colocaría en tal posición; basta apreciar con detalle este relieve para ver que no podría ajustarse a este lugar ${ }^{65}$. Este hecho, ya fue apreciado por Trillmich y es evidente ${ }^{6}$. Por otro lado, creemos que en esta propuesta de Poveda no se resuelve la escena convenientemente, ya que no resta espacio para insertar los personajes que cita. Es evidente que entre el toro y el ángulo derecho con sendos lictores no cabe espacio físico para acoger tal escena.

Teniendo en cuenta los aspectos técnicos e iconográficos, imprescindibles para aproximarse con cierto rigor al grupo relivario, nuestra idea es que el acto se desarrollaría siguiendo un suovetaurile, que es el expediente más común en estos relieves ${ }^{67}$. Esta escena, como en otros ejemplos, sería uno de los frentes de la construcción monumental.

61 Ibid., pág. 131; A. Frova, “Frammenti di rilievi marmorei lunensi con rappresentazioni architettoniche". Studie di antichitá in onore di G. Maetzke. Roma, 1984, págs. 527-533; J. MAlER, Architektur im römischen Relief. Bonn, 1985; M. TORELLI, «Topografia e iconologia. Arco di Portogallo, Ara Pacis, Ara providentiae, Templum Solis". Ostraka 1, 1. 1992, págs. 105-131.

62 La hipótesis de Trillmich, con el dibujo de U. Stadler, es la que usa Poveda, Cfr. art. Cit. Fig. 5, para plantear la incorporación del fragmento nuevo al relieve.

63 Además del repertorio tipológico citado por Trillmich en su citado artículo, valgan la reciente catalogación de J. L. DE LA BARRERA, vid. Nota infra.

64 N. ${ }^{\circ}$ Inv. 4. 410; W. TriLlmich, art cit., págs. 285, sS; J. L dE LA BARRERA, La decoración arquitectónica de los Foros de Augusta Emerita. Roma, 2000. N. ${ }^{\circ} 498$, pág. 132, lám. $158,2$.

65 En la sala de exposición del M.N.A R., la obra se ha instalado en esta zona para facilitar la comprensión del gran público, considerando esta «licencia» un pequeño sacrificio cientifico, toda vez que los profesionales conocen la bibliografia.

656 W. TRILLMICH, art. cit.

67 S. TORTORELLA, art. cit. 
Nuestra nueva hipótesis plantea la posibilidad de que el fragmento con motivo arquitectónico y remate superior de guirnalda, que en el dibujo reconstructivo de Trillmich cierra la arista derecha del relieve, pudiera pertenecer a un segundo frente relivario, también figurativo, del que no se han encontrado hasta hoy otros elementos. ¿Estamos ante dos escenas sucesivas de un acontecimiento histórico narrado en dos pasajes? Creemos que sí, y al respecto nos hallamos inmersos trabajando sobre esta cuestión en el presente.

La colocación de estos elementos arquitectónicos en cada una de las aristas de las placas hace sospechar que ambas escenas, una en cada frente monumental, arrancaban con la representación tectónica como comienzo y contexto del marco urbano en el que se estaba desarrollando la escena. Podría tratarse de sendas visiones de las puertas monumentales de acceso al Foro emeritense, que bien pudieran identificarse entre los materiales monumentales de la decoración del recinto ${ }^{68}$. Aunque, por otra parte, tampoco olvidemos que muchos de estos edificios eran a veces simbólicos e inexistentes en las propias ciudades donde se representaban, siendo meros topoi o clichés iconográficos al uso.

\section{OTROS MATERIALES DE PAN CALIENTE Y SU CONEXIÓN CON LA DECORACIÓN DEL ALTAR}

Si aceptamos la existencia de sendos frentes relivarios, conectados con el mismo conjunto monumental, y en los que una de las escenas llevaría esculpido el momento de iniciar la celebración del sacrificium, mientras la segunda escena complementaría la anterior, hemos de pensar en una estructura constructiva de cierta consideración. Las dimensiones de las placas, realizadas para adherirse a un frente arquitectónico, presuponen un fondo sustentante de envergadura una construcción de escala mayor. Esta visión de conjunto de todo el elenco de Pan Caliente, que procuramos desde el inicio de nuestra investigación, es el único camino posible para arribar al puerto final. Tan sólo con la «lectura» del relieve histórico de Agrippa y el nuevo fragmento del toro es complejo determinar que esta escena pudiera asociarse al citado altar emeritense, ¿por qué no podrían ser estos relieves de otro complejo monumental, como es el espacio del foro emeritense como sugiere J. L. de la Barrera? ${ }^{69}$. Sólo la conexión con los relievs internos nos da la clave del altar, clave que ya era

58 J. L. DE la BarRera, op. cit, passim.

69 J. L. DE la BarRera, op. cit., págs. 186-187. 
conocida por tantos colegas a los que dimos a conocer nuestras novedades en numerosas ocasiones ${ }^{70}$.

Referimos algunas líneas más arriba cómo todos los autores que estudiaron los relieves de Pan Caliente asociaron éstos al modelo del $\mathrm{Ara} \mathrm{Pacis}^{71}$, su conexión es evidente desde un punto de vista iconográfico. Trillmich en el último trabajo en que reseñó las obras del llamado relieve histórico apunta con interrogante que puedan pertenecer a un altar ${ }^{72}$, sin determinar cual.

El extenso y completo trabajo de Torelli ${ }^{73}$, donde establece la tipología de los más conocidos relieves históricos, se fue ampliando con las sucesivas entregas de Koeppe ${ }^{74}$ y otros autores ${ }^{75}$, dónde analizaban conjuntos relivarios de tipo histórico y completaban el repertorio.

Si el relieve narrativo histórico con la escena de sacrificio donde actúa Agrippa como oficiante no planteó nunca dudas respecto a su relación con estructuras monumentales, y en concreto siempre el Ara Pacis planeó y se citó como patrón o modelo inspirador, había que avanzar en el seguimiento de esta posible construcción. $Y$ aquí es donde comenzamos la investigación pormenorizada para tratar de avanzar en la fisonomía del posible monumento, enfocando el estudio de los materiales de Pan Caliente como un todo (figs. 4 y 5 )

Como parte del fondo antiguo de Pan Caliente llaman la atención dos grandes placas marmóreas con bucráneos y guirnaldas de laurel rematadas por sendas franjas decorativas en los bordes superior e inferior, entre las que se intercalan objetos de sacrificio. Ningún autor las habia asociado hasta ahora $^{76}$ al grupo del relieve histórico de Agrippa. Floriano ${ }^{77}$ sólo alude a un

10 Como mencionamos en notas precedentes la interpretación de estos relieves la hemos estado dando a conocer de modo constante desde hacia varios años, aún estando inédita

Cfr. bibliografía del conjunto de Pan Caliente. T. NOGALES, art. cit. supra.

72 W. Trill $\mathrm{MiCH}$ et alii, Hispania Antiqua, Denkmäler der Römerzeit. Mainz, 1993, pág. 290, lám. $61 \mathrm{a}-\mathrm{b}$, fig. 127 (reconstrucción)

M. TORELLI, op. cit., passim.

i4 G. KOEPPEL, «Die historischen reliefs der römischen Kaiserzeit», Bjb 183, 1983, págs. 60144; Id., "Die historischen reliefs der römischen Kaiserzeit IV», Bjb 186, 1986, págs. 1-90; Id., "The Grand Pictorical Tradition of Roman Historical Representation during the Early Empire», ANRW II, 12. 1. 1982; Id., "Official State Reliefs of the City of Rome in the Imperial Age. A Bibliography", ANRW II. 12. 1. ; Id., "Die historischen Reliefs der römischen Kaiserzeit VII. Der Bogen des Septimius Severus, die Decennalienbasis und der_konstantinsbogen", Bihr 190, 1990, págs. 1-64

75 Sirve como buena sintesis T. HOLSCHER, "IV. Bildpropaganda. Historische Reliefs", en Varios, Kaiser Augustus und Die Verlorene Republik. Berlin, 1988, págs. 351-400.

16 Como documentación de ambas obras más reciente, J. L. DE LA BaRRERA, op. cit., págs. 133-134, 165, n. ${ }^{\circ}$ 501-502, láms. 161, 1 y 161, 2, quien incluye ambas obras entre los disiecta membra del Foro.

77 A. Floriano, op. cit, pág. 181, fig. 32 (aunque él en el texto la menciona como fig. 31). 
El relieve Histórico de $M$. Agrippa, los relieves de Pancaliente y el Altar...

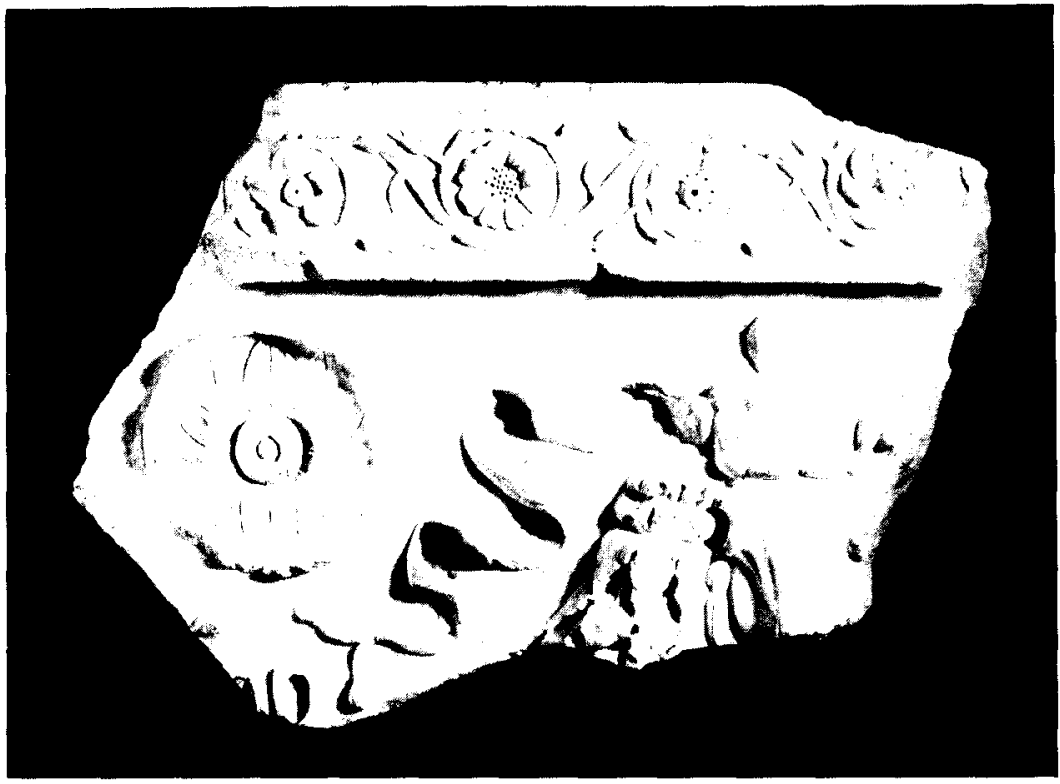

Fig. 4. Fragmento de placa-relieve de Pan Caliente. Foto: D.A.I.R. Patterson, R. 122-96-4.

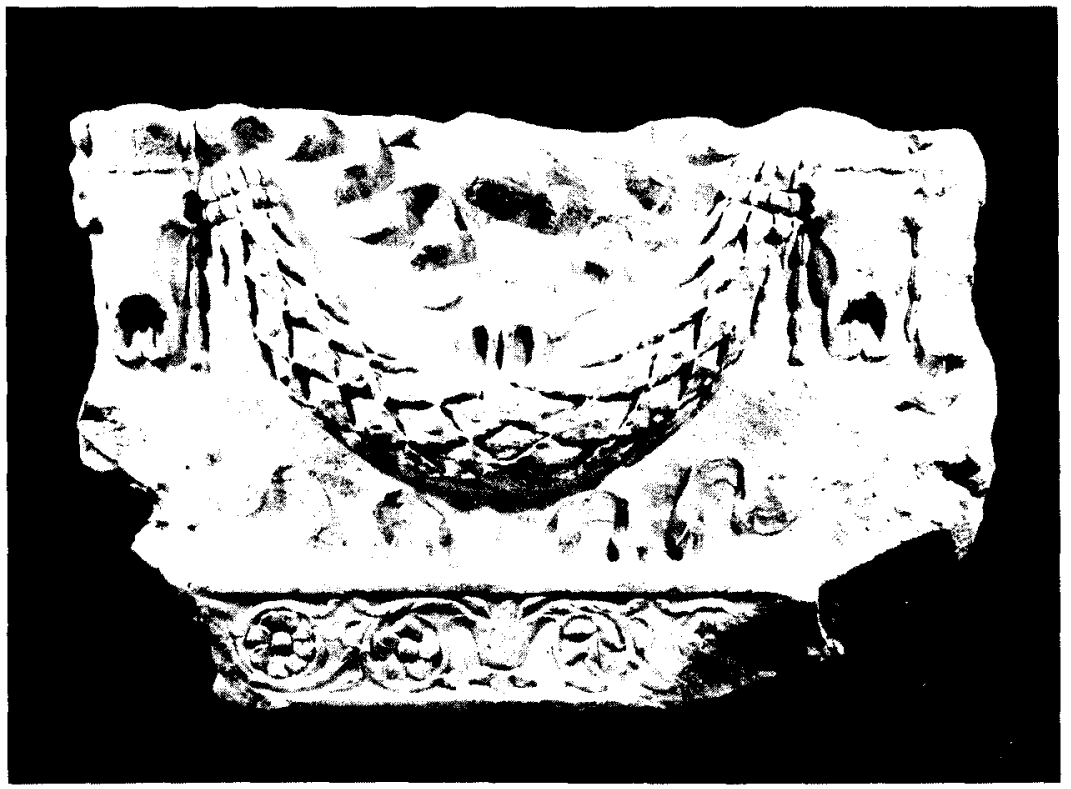

Fig. 5. Fragmeto de placa-relieve de Pan Caliente con guirnalda de laurel completa. Foto: D.A.I. R. Patterson, R. 127-96-12. 
fragmento de éstos, del que incluye en su publicación la pertinente ilustración, pero concluye considerando que no pertenece al resto del grupo. Álvarez Sáenz de Buruaga ${ }^{78}$ tampoco conecta estos dos fragmentos con los restantes. García y Bellido ${ }^{79}$ es el primero que interrelaciona todos los fragmentos relivarios de uno y otro tipo, pero sin establecer una interpretación unitaria.

Dentro de la tipología de las guirnaldas, sucesivamente analizada ${ }^{80}$, los materiales emeritenses se pueden definir con bastante precisión cronológica. Para el conjunto del relieve figurado coronado por guirnaldas de frutos Trillmich dió una fecha claudia ${ }^{81}$, no sólo por la variedad de este elemento decorativo, sino también por el estilo del relieve figurado en el que identifica a Agrippa.

Como en su día restituyó en dibujo García y Bellido ${ }^{82}$, las lastras con guirnaldas laureadas que estudiamos componían autónomamente un friso delimitado en la arista superior e inferior por un roléo floral, ya que la unión de ambos fragmentos nos permite establecer la altura total del friso. El interior de los festones que forman las guirnaldas lo ocupan las vittae y patera-urceus alternativamente. Tanto uno como otro objeto ritual poseen un trabajo minucioso ${ }^{83}$, casi de orfebreria, con una decoración floral en la patera umbilicata y un fino gallonado en el depósito del urceus (fig. 6)

Si contemplamos el interior del Ara Pacis (fig. 7), que está decorado a base de lastras con guirnaldas florales sostenidas por bucráneos ${ }^{84}$, apreciamos una evidente sintonía con el friso emeritense, si bien en el monumento metropolitano los bordes son lisos, sin bandas vegetales en ambas aristas de la placa. Existe entre la zona del zócalo y el friso de guirnaldas una franja con

78 J. Álvarez Saenz de Buruaga, art. cit., pág. 46.
79 A. Garcia y Bellido, op. cit., pág. 416-418, lám. 298.
Go. Rodenwalt, Der Sarkophag Caffarelli. Berlin, 1925; M. Stephan, Die griechische Guirlande. Berlín, 1931; A. NAPP, Bukranion und Girlande, Beiträge zur Entwicklungsgeschichte der hellenistichen und römischen Dekorationskunst. Heidelberg, 1933; M. HONROTH, Stadtrömische Girlanden. ÖAl XVII. Wien, 1971; R. TURCAN, "Les guirlandes dans I'antiquité classique", $J b A C$ $X I V, 1971$, págs. 92-139; M. MAASKANT-KLEIBRINK, "Some remarks on Roman stone garlands",

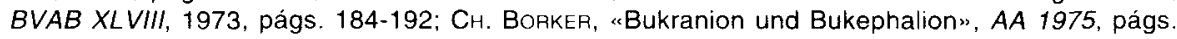
244-247; H. VON HESBERG, "Girlandenschmuck der republikanischen zeit in Mittelitalien», $R M 88$. 1981, págs. 201-246.

${ }_{81}$ W. Trillmich, art. cit., págs. 298-299. De la Barrera mantiene la fecha, vid. op. cit., n. ${ }^{\circ}$ 407-500.

82 A. Garcia y BelLido, op. cit., pág. 418, dibujo con intento de reconstrucción.

83 Sobre estos objetos se podria establecer una nutrida serie en Augusta Emerita a través de los altares funerarios que decoran sus laterales con estos útiles. Cfr. T. Nogales Basarrate, Op. cit, págs. 149 y ss.

${ }_{84}$ E. SIMON, Ara Pacis Augustae. Tübingen, 1967, págs. 13-14, figs. 7-8; M. TORELLI, op. cit., págs. 27 y ss. lám. II. 5; E. LA ROCCA, Ara pacis Augustae. In occasione del restauro della fronte orientale. Roma, 1983, pág. 14. 
El relieve Histórico de $M$. Agrippa, los relieves de Pancaliente y el Altar...

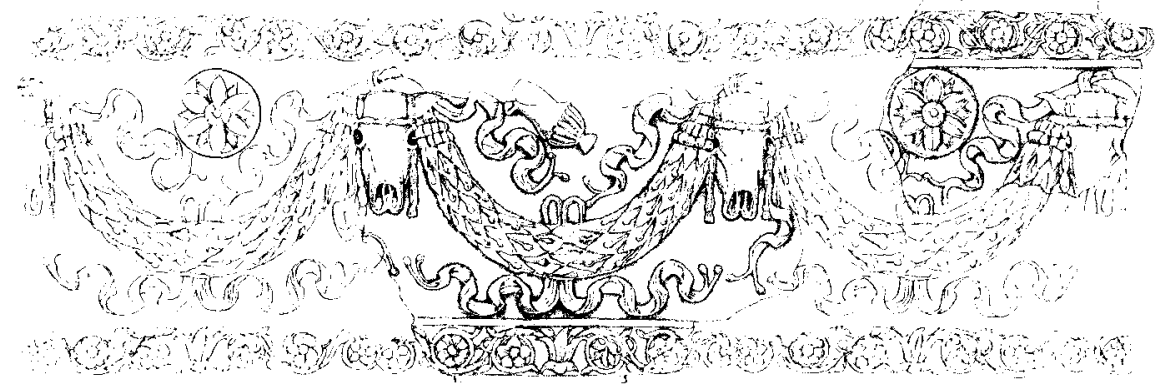

Fig. 6. Dibujo hipótesis de reconstrucción de los relieves interiores en su desarrollo. Autor: J. M. Jerez Linde, según T. Nogales.

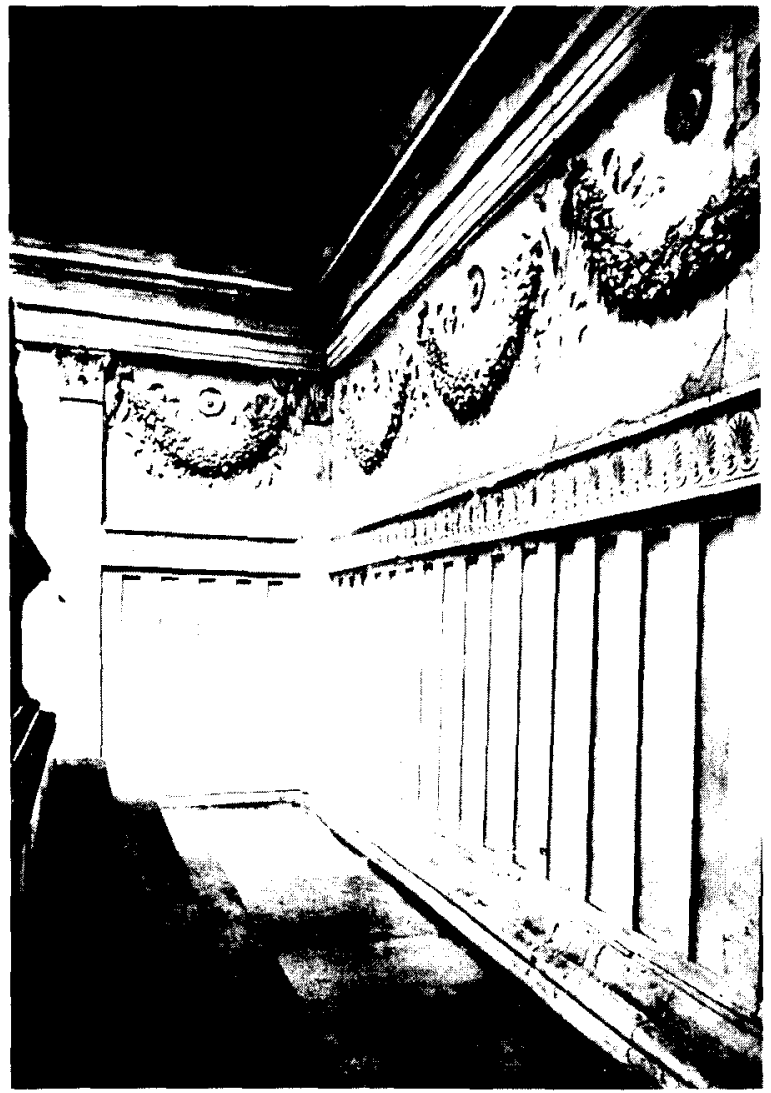

Fig. 7. Detalle interior del Ara Pacis, según E. Simon. 
palmetas que sirve de separación entre las placas ${ }^{85}$. El elemento floral, a juicio de La Rocca, se debe a una reminiscencia de la decoración original de la inauguratio ${ }^{86}$, aunque no deja de ser frecuente en la tipología al uso ${ }^{87}$.

Uno de los altares de Roma derivado iconográficamente del Ara Pacis es el Ara Pietatis ${ }^{88}$. Restos de lastras marmóreas decoradas con guirnaldas de laurel sostenidas por candelabros se han identificado con este Ara Pietatis $^{89}$. La diversificación de los motivos ornamentales originales se produce, por lo común, como resultado de la contaminación del modelo inicial. La lastra del Ara Pietatis tampoco posee franjas decorativas en sus aristas, manteniendo la morfología del modelo inspirador del Ara Pacis.

El paralelo más semejante al emeritense es una lastra con bucráneos y guirnaldas de frutos rematada también por dos listones de roléos iguales a los emeritenses, aunque intercala entre el listón y el friso central un kymation lésbico. Se encuentra conservada en el Museo de Padova y procede del foro. Ghedini apunta su probable relación con un friso monumental tipo Ara Pacis, y hace mención de la lastra emeritense como buen paralelo ${ }^{90}$. La fecha flavia, algo más avanzada que la que nos ocupa, revela la transformación de los clásicos modelos augusteos y la incorporación paulatina de cambios ornamentales en los patrones originales, que aumentan la densidad decorativa.

La similitud entre los relieves emeritenses y los modelos metropolitanos, los sucesivamente citados Ara Pacis y Ara Pietatis, nos anima a plantear que estas lastras emeritenses con bucráneos y guirnaldas de hojas de laurel formaran parte de la decoración interna de un altar monumental coIonial. La conexión entre los relieves de Pan Caliente parecía perfilarse día a día. Pero aún podemos avanzar en el análisis del grupo.

Siempre nos había llamado la atención la placa relivaria, también procedente de Pan Caliente, denominada "Arbol de la vida" ${ }^{91}$. Se trata de una obra de finísima calidad, en cuyo centro aparece representado un

\footnotetext{
85 E. Simon, op. cit., lám. II. 5; E. LA ROCCA, op. cit., pág. 14.

86 Ibid. op. cit. pág. 13.

87 D. CASTRIOTA, The Ara Pacis Augustae and the imaginery of abundance in later Greek and early Roman Imperial Art. Princenton, 1995. Figs. 52-55.

88 M. TORELLI, op. cit., págs. 63 y ss.

89 Ibid. pág. 71, lám. III. 28.

90 E. Ghislanzoni, "Padova. Scavi nel centro della cittá davanti al palazzo del Municipio», NSc 1926, págs. 341-356, fig. 11; F. GHEDNN. Sculture greche e romane del Museo Civico di Padova. Roma, 1980, pág. 76-77, n. 32.

91 A. Floriano, op. cit., pág. 182, fig. 27; Saenz de Buruaga, art. cit., págs. 44, ss; Garcia y Bellido, op. cit, n. ${ }^{\circ} 418$ F, lám. 299; T. Nogales Basarrate en Varios, Astures, pueblos $y$ culturas en la frontera del Imperio Romano. Gijón, 1995; Ead., en M. Almagro-J. M. Álvarez Martinez, op. cit. Madrid, 1998. p. 532; J. L. DE LA BARRERA, op. cit., n. ${ }^{\circ} 493$, lám. 162.
} 
magnífico laurel, sobre el que se posan y revolotean pájaros, y en cuya base se enrosca una serpiente (fig. 8)

Coincide esta placa, en su altura y grosor, con la restitución que resulta de las dos placas anteriores con las guirnaldas de hojas de laurel. Bellido llama la atención sobre su pertenencia al mismo grupo, por la semejanza de altura, pero cree que debió estar en un lugar especial de la composición ${ }^{92}$. A pesar de esta importante observación del maestro García y Bellido, nunca se volvió a reparar en este detalle y la pieza fue sucesivamente tratada como obra independiente, si exceptuamos la observación que Canto efectuó sobre la obra ${ }^{93}$.

Si bien es cierto que la placa con el laurel no posee el mismo motivo en el interior de las bandas del borde que en las placas anteriores, pues si en las precedentes iban roléos florales, en la del laurel aparecen tallos con hojas de hiedra y frutos que se incurvan al modo de roléo.

¿Cómo podría encajarse esta nueva placa con el resto? ¿Cuál sería su significado?

Tengamos presente que desde un punto de vista simbólico el laurel es el árbol de Apolo y Augusto. En el 27 a. C. fueron plantados dos laureles delante de la casa de Augusto en el Palatino ${ }^{94}$. En la iconografía augustea el laurel está presente permanentemente, con simbología de eternidad.

Buena parte de los monumentos dedicados al culto al emperador ${ }^{95}$ Ilevan laureles. El altar de los lares del Vaticano ${ }^{96}$ posee laurel. La primera ofrenda de la Galia al emperador, el altar dedicado a Roma y Augusto en Lugdunum que conocemos por las monedas ${ }^{97}$, también

92 Garcia y Bellido, op. cit., pág. 418.

9.3 A. M. CANTO, "Colonia lulia Augusta Emerita: Consideraciones en torno a su fundación y territorio", Gerión 7, 1989, pág. 171, nota 95.

94 Res Gestae Divi Aug. 34; A. AlföldY, "Die zwei Lobeerbäume des Augustus", Antiquitas 14. Bonn, 1974.

95: R. EtIEnne, Le culte impérial dans la Péninsule lbérique d'Auguste à Diocletien. Paris, 1958; FISHWICK, ICLW II, 1.

96 G. LIPPOLD, Die Skulpturen des Vatikanischen Museums. III. 1. Berlin, 1936. cat. 516 a, págs. 6365, lám. 31; B. ANDREAE et alii, Bildkatalog der Skulpturen des Vatikanischen Museums. Berlin, 1994.

97 G. FuCHS, Architekturdarstellungen auf römischen Münzen der Republik und der frühen Kaiserzeit. AMUGS I. Berlín, 1969. lám. 6, fig. 75-76; R. TURCAN, “L'autel de Rome et d'Auguste "Ad confluentem" ", ANRW II. 12. 1., 1982, págs. 607-644. Recoge la bibliografia más actualizada y abundante documentación gráfica; Y. SOLIER et alii, “Notes de numismatique Narbonnaise IV. Les monnaies découvertes à Narbonne (1938-1945) (Fouilles et collection Héléna), RAN 17, 1984, págs. 135-185; D. FISHWICK, ICLW (, 1, 1987, págs. 102-130; Id., "The Sixty Gallic Tribes and the Altar of three Gauls", Historia 38, 1989, págs. 111-112; U. SüssenBACH, "Der Reichsaltar der Roma und der Augustus in Lugdunum. Ein barbarisierter AS mit dem Bild Neros und das Problem der Nachaugusteischen Altarserien”, BJb 189, 1989, págs. 73-96. 


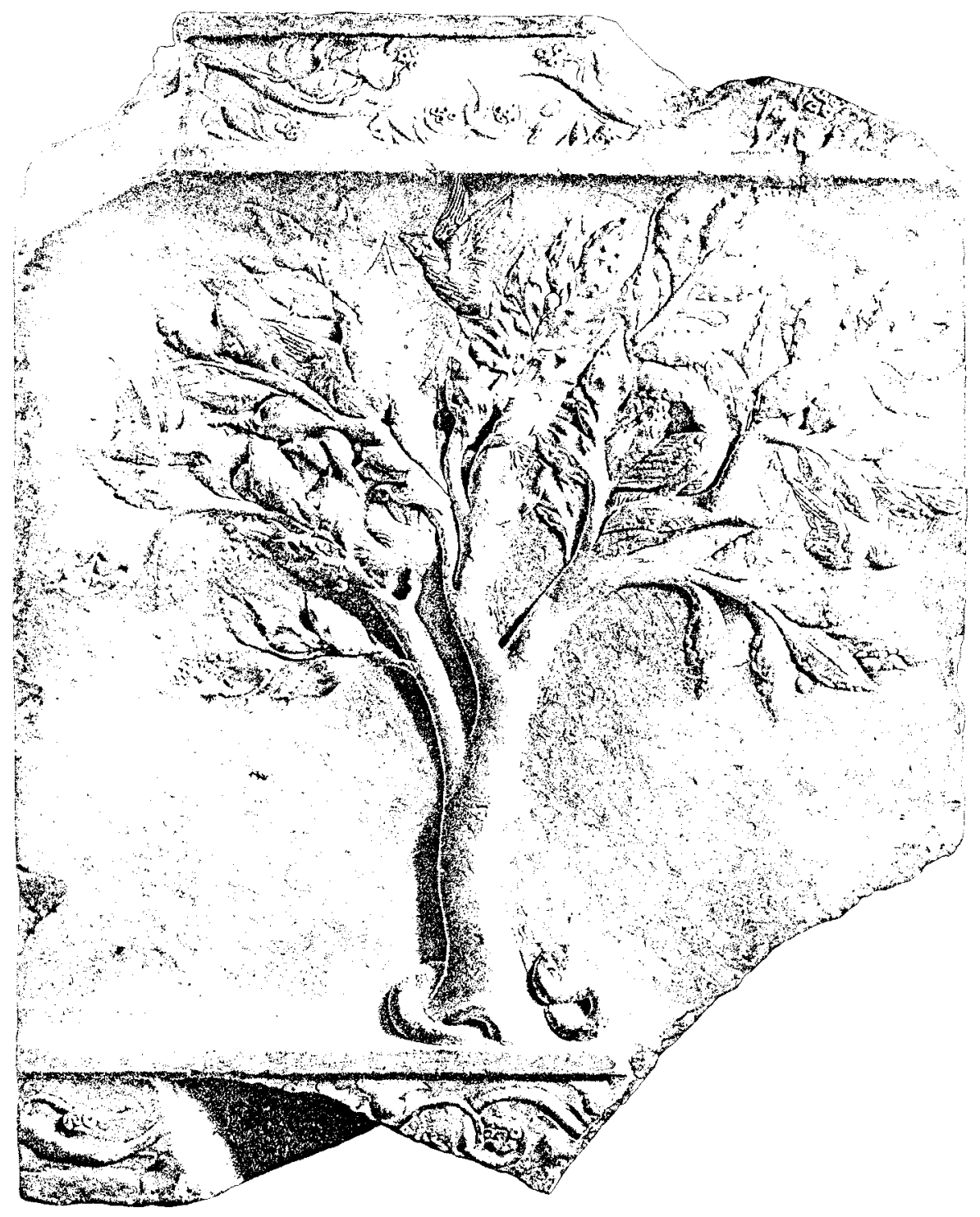

Fig. 8. Dibujo del relieve con laurel. Autor: J. M. Jerez Linde. 
tenía representados sendos laureles. Una placa procedente de las excavaciones del templo de Vienne ${ }^{98}$, e identificada con un relieve de altar, posee también un laurel picoteado por pájaros, muy parecido al emeritense.

El famoso relieve del Louvre con la escena de sacrificio muestra sendos laureles, detrás de ambos altares ${ }^{99}$. El altar de Pompeya del templo de Vespasiano posee en su cara posterior una corona de encina flanqueada por los laureles ${ }^{100}$. Desde el ámbito oficial el laurel se incorporó a la simbología general, también en el espacio privado, y no resulta extraño encontrar un gran número de arae funerarias y otros relieves con laureles en sus frentes ${ }^{101}$.

La pieza emeritense con el laurel se conectaría simbólicamente con las guirnaldas de laurel de las placas precedentes, se uniría al grupo de los relieves de Pan Caliente. No importa que las bandas de los extremos sean de diferente motivo. Si este laurel hiciera pareja con otra placa semejante, en alusión a los geminae laurus de Augusto, como en el altar de Apolo del Teatro de Arlès ${ }^{102}$, ambas placas ocuparían sendos laterales menores del recinto.

En su dia, para no relacionar las placas con coronas de laurel y ésta del laurel en árbol, uno de los argumentos que se esgrimieron fué el de su diferente tipología en la decoración de los frisos de ambas aristas. Esta divergencia no sería tal si tenemos en cuenta que las esquinas internas del monumento, donde irian las uniones de los dos tipos de lastras, podrían estar ocupadas por pilastras, tal como es visible en el Ara Pacis ${ }^{103}$. Las pilastras de ángulo servirían para tapar las uniones de las placas y, ¿por fig. 54 .

98 A. Pelletier, “Les fouilles du “Temple de Cybèle" à Vienne", RA 1966, 1, págs. 113-150

99 G. KOEPPEL, "Die historischen Reliefs der römischen Kaiserzeit», Bjb 183, 1983, págs. 60144, fig. 34, cat. 30.

${ }_{100}$ I. S. RYBERG, op. cit., pág. 82, lám. XXVI, fig. 38 b; G. NieBling, "Der Tempel und Altar des Vespasian in Pompeji», FuF 1957, págs. 23-29; J. J. DobBins, "The Altar in the Sanctuary of the Genius of Augustus in the Forum at Pompeii», RM 99, 1992, págs. 251-263, láms. 73-74. Este autor cree que existen dos fases en el altar; una primera augustea para los paneles relivarios, y una segunda flavia de reforma del monumento.

101 Los ejemplos son tan numerosos que ponen de manifiesto la extensión y popularidad de este simbolo. Algunos metropolitanos, Cfr.: LIPPOLD, op. cit., III, 1 cat. 559, lám. 75 y III, 2 , págs. 44-45, lám. 25. En la península citemos el ejemplo del Museo Arqueológico Nacional, vid. GARCIA Y BELLIDO, op. cit, pág. 302, lám. 243.

102 E. ESPERANDIEU, Recueil général des bas-reliefs de la Gaule romaine I. Paris, 1907. n. 138; P. Gros, “Un programme augustéen: le centre monumental de la Colonie d'Arles", JdI 102, 1987, págs. 339-363, fig. 13.

103 E. SIMON, op. cit., lám. 8. 
qué no?, permitirian un cambio decorativo en un elemento tan secundario como es el friso de remate de la placa. Otra posibilidad, habida cuenta del carácter unitario de los frisos relivarios narrativos con representaciones escenográficas históricas, es que este relieve del laurel fuera en la cara externa del monumento, como apreciamos en el caso del altar de Lugdunum ${ }^{104}$.

Si aceptamos la unidad de todos estos relieves decorativos en un mismo complejo relivario, la siguiente cuestión que se nos plantea, como es lógico, es la identificación de este monumento, su posible datación y emplazamiento original.

\section{LOS RELIEVES DE PAN CALIENTE: DECORACIÓN DEL ARA PROVIDENTIAE DE LAS ACUÑACIONES MONETALES}

A tenor del formato relivario monumental considerable que caracteriza a las obras del grupo de Pan Caliente, estos paneles se pueden asociar a una zona de cuerpo central de la estructura superior de un altar de culto ${ }^{105}$, lo que se define como templum minus o templum in terris, cuyo prototipo más representativo es el citado Ara Pacis ${ }^{106}$, a partir del cual se gestaron toda una serie de construcciones análogas vinculadas al culto imperial de la dinastía julio-claudia ${ }^{107}$.

La Colonia Augusta Emerita no fue ajena a este programa monumental que se extendió desde Roma, y que estaba presente en todo el occidente imperial. Este proceso creemos que debe enmarcarse dentro de un panorama peninsular, sobre el que ya hemos efectuado algunas observaciones ${ }^{108}$.

Las dificultades de la arqueología urbana unidas al azar en los hallazgos coloniales, entre los que falta la evidencia epigráfica, hacen compleja la localización de monumentos de este tipo. ¿Qué altar sería? ¿Cuál sería su ubicación? ¿En qué momento se erigió y cual era su aspecto?. Intentaremos aproximarnos a estas cuestiones.

104 Cfr. nota supra n. 97.

105 R. Ginouves-A. M. Guimier-Sofbets, “Les autels de I'Antiquité classique: Problèmes de description", L'Espace sacrificiel dans les civilisations mediterranéennes de l'Antiquité. Lyon, 1991, págs. 277-290.

106 SimON, Op. cit, págs. 9, ss; TORELl, op. cit., págs. 31, ss; LA RocCA, op. cit., págs. 13 y ss. M. TorelLI, Op. cit, págs. 63, ss; FISHWICK, ICLW I, 1, págs. 169 y ss.

108 En este sentido preparamos un estudio más amplio sobre otros posible materiales decorativos hispanos y su conexión con altares similares al que nos ocupa. 
Un repertorio excepcional para recuperar datos monumentales es la iconografía monetal ${ }^{109}$, y en caso de la augustana ${ }^{110}$ son varios los temas representados. De los monumentos emeritenses se hallan representados la puerta de la ciudad con su doble vano, el Templo tetrástilo dedicado a Augusto o el ara Providentiae ${ }^{111}$. Estos tres edificios se muestran con toda suerte de detalles, sin embargo otros podrían aparecer aludidos con simples símbolos figurativos ${ }^{112}$. La numismática usa el recurso figurativo como topos ideológico, y muchas construcciones que se aprecian en las

109 Citemos como muy interesante el reciente trabajo de F. Chaves, E. MELChOR, M. OrIA y R. GiL, "Los monumentos en la moneda hispanorromana", Numismatica e Antichitá Classiche. Quaderni Ticinesi XXIX, 2000 (en prensa). Agradecemos al Dr. De Melchor el habernos facilitado la consulta de las pruebas de imprenta de este interesante y novedoso trabajo.

110 Sobre numismática emeritense, Cfr.: E. FLOREZ, Medallas de las colonias, municipios y pueblos antiguos de España. Madrid, 1757; A. HEISS, Description Générale des Monnaies antiques de IEspagne. Paris, 1870; A. DELGaDo, Nuevo método de clasificación de las medallas autónomas de España. Tomo II. Sevilia, 1873; A. VIVEs Y Escudero, La moneda hispánica. Madrid, 1926; A. GARCIA DE LA FUENTE, "La moneda emeritense", R.C.E.E. 1929, págs. 27-48; H. Solis, "Monedas autónomas españolas. Emerita Augusta", R.C.E.E. 1930; O. GIL FARRÉS, "La ceca de la Colonia Augusta Emerita", AEspA XIX, 1946, págs. 209-249; A. BELTRAN, "LoS monumentos en las monedas hispanoromanas", AEspA XVI, 1953, págs. 39-66; Id., "Las monedas romanas de Mérida: su interpretación histórica", Augusta Emerita. Actas del Bimilenario de Mérida. Madrid, 1976, págs. 93-106; J. P. Bost y F. Chaves TRISTÁN, “Le rayonnement des ateliers de Pax lulia, Ebora et Emerita: essai de géographie monétaire des réseaux urbains de la Lusitanie romaine à l'époque julio-claudienne". Les villes de la Lusitanie romaine. Bordeaux, 1990, págs. 115-121; C. BLAzQuez CERRATO, La dispersión de las monedas de Augusta Emerita. Mérida, 1992 (Cuadernos emeritenses 5); A. VELAZOUEZ JIMENEZ, Repertorio de bibliografia arqueológica emeritense. Cuadernos emeritenses-6. Mérida, 1992, págs. 113-118; F. CHAVES $\gamma$ OTROs, art. cit.

111 A. Beltran, art. cit., AEspA XVI, 1953, pág. 55, figs. 22-23; Id., art. cit., Augusta Emerita. Actas del Bimilenario de Mérida. Madrid, 1976, págs. 93-105. Cfr. Bibliografía precedente; G. FuCHS, Architekturdarstellungen auf römischen Münzen. AMUGS I. Berlin, 1969, pág. 42, lám. 8 101-103. La posible localización de la puerta se indica en: J. M. Álvarez MARTinez, "Excavaciones de Augusta Emerita", Coloquio de Ciudades modernas superpuestas a las antiguas. (Zaragoza, 1983). Madrid, 1985, págs. 35-49. El templo tetrástilo, identificado por A. Velázquez con el templo de la Calle Holguín emeritense, vid. F. DE Asís ESCUDERO y ESCUDERO, “Los templos en las monedas antiguas de Hispania», Numisma $X X X I$, n. ${ }^{\circ} 168-171,1981$, págs. 181-184. ; sobre el Ara Providentiae vid. también: R. ÉTIENNE, op. cit, págs. 378-379; D. FISHWICK, ICLW, 1. Leiden, 1987, págs. 180-189; G. GAMER, "Altäre auf hispanischen Münzen", Praestant interna. Festschrift für Ulrich Hausmann. Tübingen, 1982, págs. 338-348; J. L. DE LA BARRERA, op. cit, págs. 178-179, lám. 183.

112 En algunos trabajos se habian identificado las representaciones monetales de la cabeza de anciano barbado y de la "ninfa» con los acueductos emeritenses. Canto, en su dia, revisó estas identificaciones: A. M. CANTO, "Sobre la cronología augustea del acueducto de los Milagros de Mérida", Homenaje a Sáenz de Buruaga. Madrid, 1982, pág. 187ss. En su reciente trabajo sobre el culto a la confiuencia, vid. CANTO Y OTROS, art. cit., MM 38, 1997, págs. 274-275, se propone la identificación del tipo monetal con ambos rios. Nos parece acertado considerar que la iconografia de la figura identificada con una "ninfa" podria responder perfectamente a la personificación del joven Barraeca, Albarregas, pues los rasgos anatómicos destacan ciertos elementos andróginos en el perfil monetal, J. L. Mosquera y T. Nogales Basarrate, Aquae Aeternae. Una ciudad sobre el rio. Badajoz, 1999, págs. 62-63. 


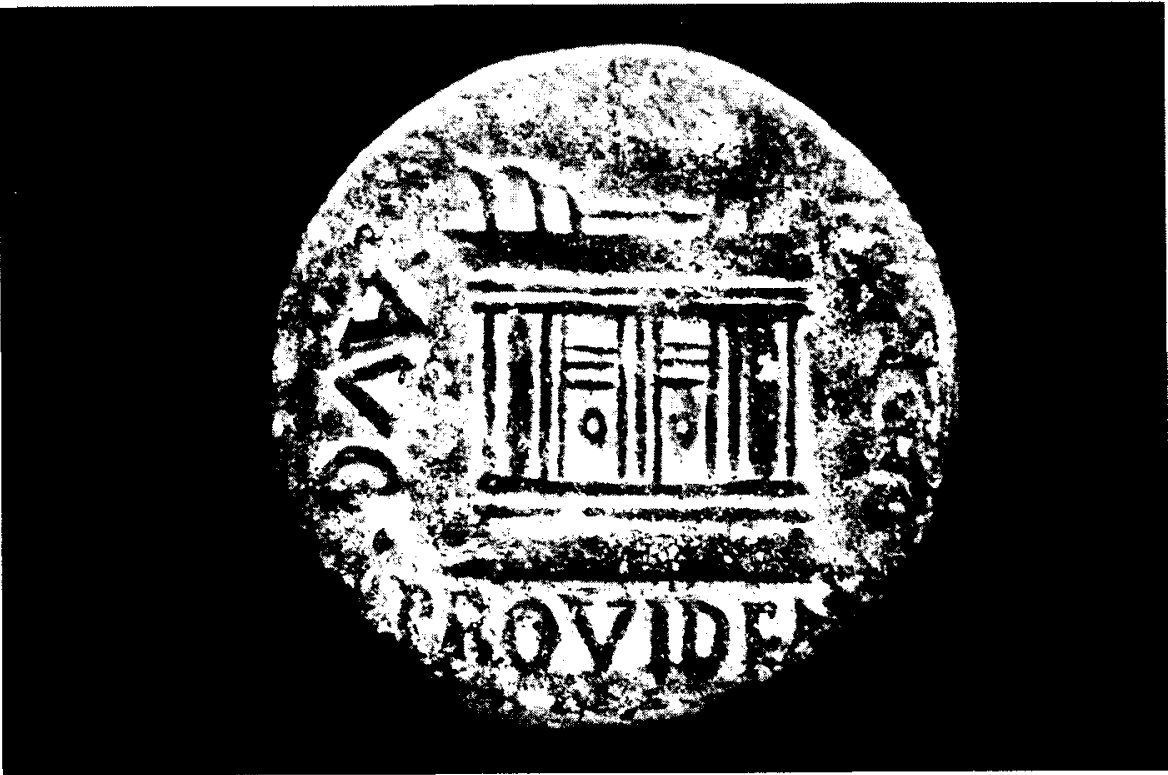

Fig. 9. Moneda emeritense con la representación del Ara Providentiae. Foto: Archivo M.N.A.R.

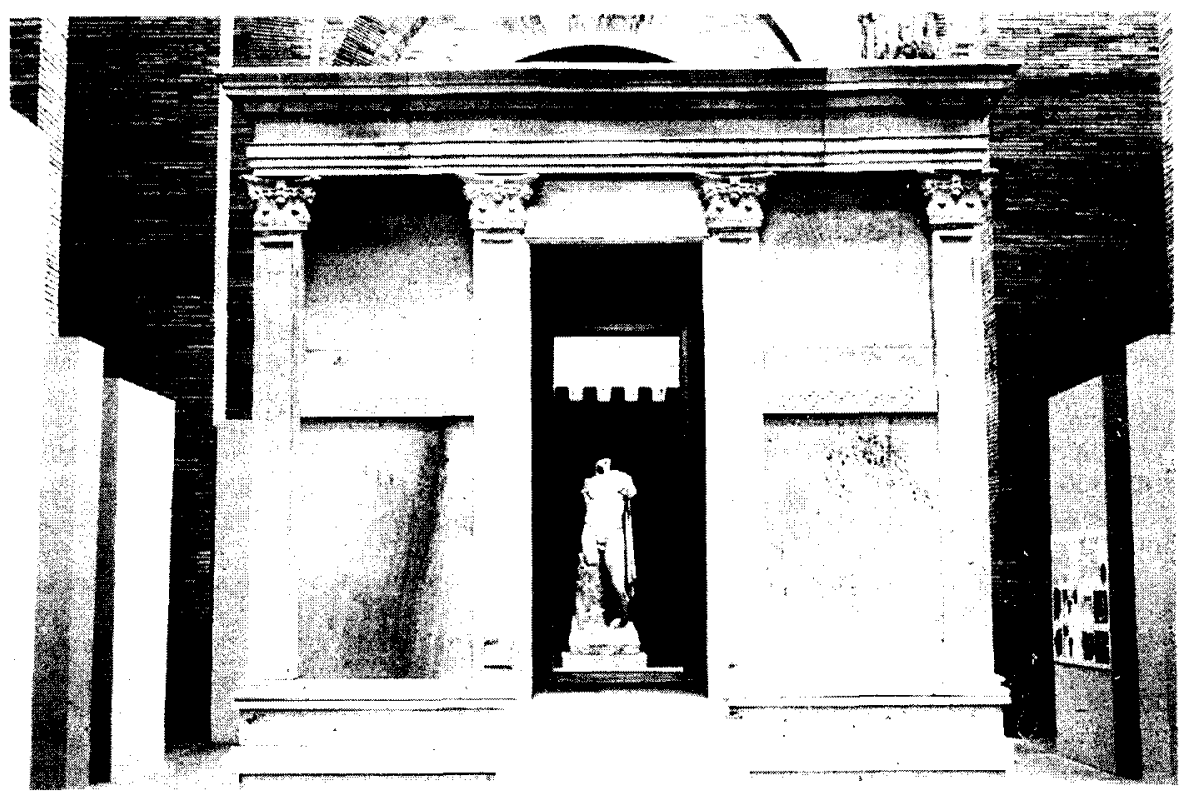

Fig. 10. Maqueta-Reconstrucción del Altar a gran escala para la Exposición "Hispania. El legado de Roma". Foto: Archivo del M.N.A.R. 
monedas tienen un valor documental excepcional ${ }^{113}$, pero también es cierto que algunas representaciones monetales no son sino prototipos de uso propagandístico, y muchas veces proyectos que no llegaron a ejecutar$\mathrm{se}^{114}$, tanto en la propia capital del Imperio como en núcleos de singular interés ${ }^{115}$.

El Ara Providentiae ${ }^{116}$ en los tipos monetales emeritenses (fig. 9) responde a un esquema monumental muy sencillo, que repite con fidelidad el esquema de los ases metropolitanos de Tiberio que llevan en su reverso el Ara Providentiae 17 , altar dedicado a esta virtud imperial y recordado por los Acta Fratrum Arvalium ${ }^{118}$. Torelli alude al proceso de imitación que Tiberio inicia sobre el modelo del Ara Pacis, que tiene su nutrida secuencia monetal y monumental. Si se desconoce cómo eran físicamente muchos de estos altares, sabemos que ideológicamente respondian a un plan bien trazado ${ }^{19}$, ya que implícita o explícitamente podían estar dedicados al numen del emperador con la ayuda de la personificación de una virtud: Pax, Providentia, Pietas... ${ }^{120}$.

Este Ara Providentiae, tanto en las acuñaciones metropolitanas ${ }^{121}$ como emeritenses ${ }^{122}$ de época tiberiana adopta la forma de un templum minus, y como tal se representa de un modo sencillo y esquemático: podium escalonado, cuerpo central compartimentado por pilastras que separan las puertas y coronamiento con destacadas acróteras? angulares $^{123}$.

113 F. Chaves, "Monedas para una sociedad nueva", en J. M. Álvarez-M. Almagro-Gorbea, En el año de Trajano. Hispania. El legado de Roma. Madrid, 1998, pág. 90.

114 D. FiSHWICK, "Coins as evidence: Some Phantom Temples", Echos du monde classique. Classical Views, XXVIII, 1984, págs. 263-270

115 G. Fuchs, op. cit. ; Varios, Bauten Roms auf Münzen und Medaillen. München, 1973; F. PRAYON, "Projektierte Bauten auf römischen Münzen", Praestant interna. Festchrift für Ulrich Hausmann. Tübingen, 1982, págs. 319-330, láms. 71-72.

116 G. GAMER, art. cit., lám. 75-6.

117 M. TORELLI, op. cit., lám. III. 5.

118 Ibid., págs. 64 y 84.

119 D. MANNSPERGER, “ROM. ET AVG. Die Selbstdarstellung des Kaisertums in der römischen Reichsprägung", ANRW II. 1, 1974, pág. 949; A. MLASOWSkY, "NOMINI AC FORTUNAE CAESARUM PROXIMI. Die Sukzessionspropaganda von Augustus bis Nero im Spiegel der Reichsprägung und der Archäologischen Quellen», Jhb 111, 1996. pp249-388.

120 G. G. BELLON!, "Significati storico-politici delle figurazioni e delle scritte delle monete da Augusto a Traiano (Zecche di Roma e “imperatorie')", ANRW II. 1, 1974, págs. 997-1144; A. Mlasowsky, art. cit, págs. 66 y ss.

$121 \mathrm{H}$. Mattingly, Coins of the Roman Empire in the British Museum. I. Augustus to Vitellius. London, 1965, pág. 141, lám. 25, 12-26, 2.

122 O. GIL FARRES, art. cit., figs. 113-117-124, 150-155; G. GAMER, art. cit., pág. 345, lám. 75, 6.

123 Son interprestadas como llamas del Ara por Mattingly. 
Si comparamos las representaciones monetales hispanas de altares de similar cronologia ${ }^{124}$, Tarraco, Emerita, Italica e llici, cada tipo difiere de los demás, seguramente porque cada altar tenía una fisonomía distinta.

El impresionante y temprano altar de Tarragona ${ }^{125}$ de culto imperial ${ }^{126}$, cuya imagen en las monedas es de tal detallismo que permite restituir la ornamentación externa con bastante fiabilidad ${ }^{127}$, responde a otro esquema constructivo del emeritense. El monumento tarraconense está formado por un podio moldurado, un cuerpo central relivario con pilastras en los ángulos, insignia-clupeus virtutis? y bucrania sosteniendo guirnaldas, sendos pulvini florales ${ }^{128}$ en el coronamiento y la prodigiosa palma emergiendo del monumento ${ }^{129}$. Lamentablemente, no se ha determinado ningún elemento de este altar ni tampoco se conoce con seguridad su emplazamiento original ${ }^{130}$.

Entre el italicense y el emeritense, ambos dedicados a la providentia, el más parecido al patrón metropolitano es el emeritense. Martin cree que esta copia exacta del cuño metropolitano es una muestra de adhesión al régimen imperial asegurado bajo Tiberio ${ }^{131}$, y que ello no presupone la existencia física del altar en la Colonia, opinión que Fishwick ${ }^{132}$ considera.

El último aspecto por cerrar sería la cronología de altar monetal, de fines de época tiberiana, y los relieves de Pan Caliente, de fecha tiberioclaudia. ¿Qué explicación podríamos darle a este pequeño desfase entre una y otra fecha?

En primer lugar, debemos incidir en que sólo se trataría de apenas un decenio, lapso de tiempo comprensible para mediar entre el proyecto, reflejo del modelo metropolitano, y la final ejecución monumental del edificio. Tampoco olvidemos que, y ésta es otra opción que entra dentro de lo

124 G. GaMer, art. cit., lám. 75.

125 G. AlFÖLYY, s. v. "Tarraco", RE suppl. 15, 1978, 600.

126 R. Etienne, op. cit, págs. 362, ss; D. Fishwick, «The Altar of Augustus and the Municipal Cult of Tarraco", MM 23, 1982, págs. 223-233; Id., ICLW I, 1, págs. 171-179.

127 G. Gamer, art. cit., lám. 75, 3-4.

128 El tipo de puivinus monumental se puede observar: E. LA RoccA La riva a mezzaluna. Culti, agoni, monumenti funerari presso il Tevere nel Campo Marzio Occidentale. Roma, 1984. lám. XVII-XVIII, es uno perteneciente al cenotafio de $M$. Agrippa.

129 D. FISHWICK, ICLW I, 1, pág. 171.

130 G. ALFOLDY, art. cit.; TH. HAUSCHILD, "Römische Konstruktionen auf der Oberen Stadterrasse des antike Tarraco", AEspA 45/47, 1972-74, págs. 3-44; TH. HauschilD, Hispania Antiqua. . ., págs. 323-324.

131 J. P. MARTIN, Providentia deorum. Recherches sur certains aspects religeux du pouvoir impérial romain. Rome, 1982, págs. 114-118. 
plausible, la monumentalización y marmorización pudo producirse en un segundo estadio del complejo.

\section{LA UBICACIÓN DEL ALTAR Y LOS TALLERES ESCULTÓRICOS DEL FORO EMERITENSE}

Los monumentos conmemorativos, y especialmente los altares, se situan siguiendo, por lo común, normas de carácter simbólico ${ }^{133}$. Los factores ideológico-religiosos tienen su paradigma en el detallado y minucioso programa del Ara Pacis ${ }^{134}$.

Es evidente que el altar dedicado a la providencia imperial debió hallarse en pleno Foro. Su existencia ha reforzado, entre otras muchas otras argumentaciones, la pujanza que el culto imperial alcanzó en esta zona occidental de Hispania y su temprana introducción en la capital lusitana ${ }^{135}$. Pero no es ésta una prueba aislada en la iconografía emeritense, hay varias más que certifican esta densidad de imágenes urbanas de culto imperial.

Del recinto del teatro, concretamente de su porticus post scaenam, proviene el grupo imperial con el retrato de Augusto velado y los jóvenes herederos julio-claudios ${ }^{136}$. También del espacio teatral, de su scaenae frons, son las series estatuarias de emperadores en traje militar, y la conocida como emperador divinizado tipo Júpiter ${ }^{137}$; en época trajanea se erige un sacrarium en el teatro emeritense ${ }^{138}$. Todas éstas son huellas iconográficas que abundan sobre este aspecto cultual imperial de los espacios mediante el uso de imágenes ${ }^{139}$.

132 FISHWICK, ICLW I, 1, págs. 180-183.

133 M. ToRELli, art. cit., Ostraka I, 1, 1992, págs. 105-131.

134 A. H. Borbein, "Die Ara Pacis Augustae-Geschichtliche Wirkichkeit und Programme", Jdl 90, 1975, págs. 242, ss; E. BuCHNER, "Solarium Augusti und Ara Pacis", RM 83, 1976, págs. 319, ss; O. DRAGER, Religionem significare. Studien zu Reich Verzierten römischen Altären und Basen aus Marmor. Mainz, 1994. passim.

${ }_{135}$ R. EtIENNE, op. cit., passim; Fishwick, ICLW I, 1, págs. 180-183.

136 W. TRILLMICH, "Novedades en torno al programa iconográfico del Teatro de Mérida", en T. Nogales Basarfate (ed.), Actas de la / Reunión sobre escultura romana en Hispania. Mérida, 1992). Madrid, 1993, págs. 113-123; Id. Hispania Antiqua, págs. 124 y ss, fig. 2, págs. 281 y ss., lám. 49; T. Nogales Basarite, en Varios, la Mirada de Roma. Retratos de los Museos de Mérida, Toulouse y Tarragona. Barcelona, 1993, págs. 187 y ss, n. ${ }^{\circ} 134$. W. Trillmich, Die Präsenz des Kaiserhauses im Theater der Colonia Augusta Emerita. (en prensa).

137 Id., Hispania Antiqua..., págs. 282 y ss, lám. 51, a-b; FISHWICK, ICLW II, 1, pág. 523; Trillmich,

138 W. TrILLMICH, "Un sacrarium de culto imperial en el teatro de Mérida", Anas 2-3, págs. 1989-1990, págs. 87-102.

139 TH. PEKARY, Das römische Kaiserbildnis in Staat, Kult und Gesellschaft. Das römische Herrscherbild III. Berlin, 1985 
En pleno recinto del Foro ${ }^{140}$ municipal se halla el Templo de Culto imperial, el llamado de Diana ${ }^{141}$, de cuyo contexto también proceden una serie de estatuas imperiales que mantienen la iconografía de los tipos divinizados ${ }^{142}$.

La zona superior del Foro, los conocidos como pórticos del Foro ${ }^{143}$, desarrollan un espléndido programa decorativo bajo los dictados del Forum Augustum ${ }^{144}$, y viene a ser en la Península el mejor ejemplo constatado de un probable augusteum ${ }^{145}$, en curso de estudio ${ }^{146}$. Los ciclos estatuarios, con la incorporación de los grupos de Eneas ${ }^{147}$ y Rómulo?, no buscan sino resaltar entre los provinciales la presencia efectiva de Roma.

¿Dónde se alzaría majestuoso este Ara Providentiae?. El carácter de la virtud imperial ${ }^{148}$ inclina a considerar que su espacio más lógico fuera el recinto del llamado Foro Provincial, que ha sido sucesivamente discutido y

140 J. M. Álvarez Martínez, "El foro de Augusta Emerita», Homenaje a Sáenz de Buruaga. Madrid, 1982, págs. 53, ss; FisHWICK, ICLW II, 1, pág. 520.

${ }_{141}$ Id., "El Templo de Diana", Templos romanos en Hispania. Cuadernos de arquitectura romana. Madrid, 1991, págs. 83-93. (vid. bibliografia precedente). TH. HausCHILD, Hispania Antiqua, págs. 276-279, lám. 44-45.

${ }_{142}$ H. HÄNLEIN-SCHÄFER, Veneratio Augusti. Eine Studie zu den Tempeln des ersten römischen Kaisers. Roma, 1985, págs. 81 y ss.; T. Nogales BASARRATE, "Programas iconográficos del Foro de Mérida: el templo de Diana", Actas de la ll Reunión sobre escultura romana en Hispania. Tarragona, 1996, págs. 115-134.

143 J. M. Álvarez Martinez-T. Nogales Basarrate, "Schéma urbain d'Augusta Emerita: le portique du forum", Akten des XIII. Internationalen Kongresses für Klassische Archäologie. (Berlin, 1988). Mainz am Rhein, 1990, págs. 336-338.

144 W. TfILLMICH, «Gestalt und Ausstatung des 'Marmorforums'in Mérida. Kenntnisstand und Perspektiven", MM 36, 1995, págs. 269-291. láms. 28-30; Id. “Reflejos del programa estatuario del forum Augustum en Mérida", Actas // Reunión sobre escultura romana en Hispania. (Tarragona, 1995). Tarragona, 1996, págs. 96-108; Id., “El modelo de la metrópoli», Hispania romana. Desde tierra de conquista a provincia del Imperio. Roma, 1997, págs. 131, ss.; J. L. DE LA BARRERA, La decoración arquitectónica de los foros de Augusta Emerita. Roma, 2000.

145 Álvarez MARTinez fué quién primero denominó así a este espacio, que muestra grandes concomitancias con los patrones de estos recintos, Cfr.: K. TUCHELT, “Zum problem “Kaisareion-Sebasteion». Eine Frage zu den Anfängen des römischen Kaiserkultes", IM 31 , 1981, págs. 167, ss; P. Gros, "L'Augusteum de Nîmes", págs. 123-134. En nota 1 recoge toda la biliografía fundamental; $\mathrm{H}$. HÄNLEIN-SCHÄFER, op. cit., págs. 10-12; FISHWICK, ICLW II, 1 , págs. 520 y ss.

146 Sobre los ciclos decorativos del Foro tenemos en curso un programa de investigación, en colaboración con el DAl-Berlín con el Dr. Trillmich. Actualmente contamos con el patrocinio de la Obra Social de Caja Duero, entidad que nos ha facilitado ayuda humana y material en un proyecto por nosotros dirigido desde el área de investigación del MNAR.

147 J. L. DE LA BARRERA-W. TRILLMICH, "Ein Wiederholung der Aeneas-Gruppe vom Forum Augustum samt ihrer Inschrift in Mérida (Spanien)", RM 103, 1996, págs. 119-138, láms. 28-39.

148 M. P. Charlesworth, «Providentia and Aeternitas", Harv. Theol. Rev. 29, 1936. p107, ss; E. ForeIS, Municipal virtues in the Roman Empire. Stuttgart, 1996. 
cuestionado ${ }^{149}$, aunque existe la evidencia arquitectónica de un Templum ${ }^{150}$ y una puerta monumental de ingreso en el denominado Arco de Trajano que serviría de límite del área oficial ${ }^{151}$ asociada al Capitolio colonial ${ }^{152}$. De allí pudieran proceder esculturas de tipo colosal que mencionan diversos autores ${ }^{153}$. La mayor cercanía de esta zona con el área de Pan Caliente, que a priori podría tenerse en cuenta a la hora de relacionar la procedencia original de las obras y su espacio de aparición, se rinde más compleja al componer el grupo numerosos fragmentos de clípeos y cariátides de la zona del otro foro. Parece más probable que, al proceder a amortizar las lastras escultóricas para la construcción de la cloaca de Pan Caliente ${ }^{154}$, se recogieran todas del mismo recinto, aunque el argumento no es concluyente, habida cuenta de la constante reutilización de las obras marmóreas de origen más que distinto y distante. Pensemos en los "anticuarios» que se dedicaban al acarreo sistemático de las piezas y a su ulterior venta desde siglos anteriores, en el ejemplo bien conocido del Templo de Marte ${ }^{155}$ ó el Obelisco de Santa Eulalia, entre otros ${ }^{156}$.

De situarse el Altar en pleno Foro Provincial su espacio más lógico sería el tramo comprendido entre el Arco de Trajano y el Templo de la

149 J. M. Álvarez Martinez, art. cit. «El foro...»; W. Trlelmich, «»Foro provincial und Foro municipal in den Hauptstädten der drei hispanischen Provinzen: eine Fiktion", Ciudad y comunidad civica en Hispania en los siglos II-III d. C. (Madrid, 1990). Madrid, 1994, págs. 115-124; Id., "los tres foros de Augusta Emerita y el caso de Corduba», en P. LEón (ed. ), Colonia Patricia Corduba. Una reflexión arqueológica. Córdoba, 1994, págs. 175-195; Sobre la arquitectura del recinto, J. L. DE LA BARRERA, op. cit., págs. 178-179.

150 El templo tetrástilo de las monedas se ha identificado con el localizado en la zona alta de la Calle Holguín, el capitolio emeritense, que al igual que el de las acuñaciones tiberianas posee cuatro columnas de enormes dimensiones en su fachada principal. Para la bibliografía del templo vid. bibliografia supra.

151 J. ARCE, "Arcos romanos en Hispania: una revisión", AEspA_60, 1987, págs. 73-88; J. M. Álvarez Martinez y otros, Conjunto arqueológico de Mérida. Patrimonio de la Humanidad. Salamanca, 1994, págs. 74-78; A. E. SHECKLER, Roman Honorary Arches in Iberia. Boston, 1991 (Diss.); A. Nünnerich-Asmus, «Strassen, Brücken und Bögen als Zeichen römischen Herrschaftsanspruchs", en W. TrILLMICH et alii, op. cit, págs. 121-157; X. DuPRE RAventós, "Los arcos honoríficos", En el año de Trajano. Hispania el legado de Roma. Madrid, 1998, págs. 159-162.

152 En el capitolio de brescia, vid.: H. GABELMANN, “Altäre im Kapitol von Brescia", RM 76, 1969, págs. 219-238, láms. 68-75.

153 Vid. A. VelAZQUEZ, op. cit., págs. 13-26.

154 Gracias a la amabilidad y disposición, constantes, de D. Juan Antonio Diaz Pintiado, pudimos visitar la zona de los hallazgos de Pan Caliente junto con el Dr. Trillmich. La acertada visión de J. A. Díaz Pintiado nos aclaró algunas cuestiones sobre la topografía y hallazgos en la zona. Vaya nuestro reconocimiento por su labor en la arqueología emeritense.

Las casas construidas hacia 1934, fecha de la aparición de los relieves, están en la parte baja. La reutilización en la cloaca pudo realizarse en época tardia.

15.5 P. LEÓN, "Los relieves del Templo de Marte en Mérida", Habis 1, 1970, págs. 181-197.

156 J. L. de la Barrera, El Obelisco de Santa Eulalia. Mérida, 1992. 
Calle de Holguín, siguiendo un expediente bastante frecuente, que analizaremos más adelante.

Una segunda posibilidad, de localizar el Ara, y en este caso se haría más complejo que se tratara de la dedicada a la Providentia, en la plaza del Templo de Diana, tiene también elementos de apoyo. El que acabamos de mencionar de la unidad de los materiales de la cloaca de Pan Caliente. Un segundo punto se podría esgrimir teniendo en cuenta la cronología augusteo-tiberiana del Templo de Culto imperial o de Diana ${ }^{157}$, fecha que enlazaría con la acuñación emeritense. El tercer elemento que cabría sopesar sería la identificación del espacio en el que se desarrolla la escena del relieve. ¿Se trata del Foro colonial?. En ese caso podría verse en el arco monumental de los ángulos de cada panel del ara no ya la puerta de entrada en la ciudad, sino un arco de acceso al recinto forense tal como se ha apuntado que debiera existir entre las dos estructuras, el llamado "foro viejo" y el «foro de mármol» por Trillmich ${ }^{158}$. La tipología arquitectónica parece poseer una rosca del arco moldurada, más propia de un arco honorifico que de una estructura defensiva ${ }^{159}$, aunque este detalle cuadraría también con la posibilidad de que estemos ante la visión relivaria del arco de Trajano, y en consecuencia de la puerta de ingreso al Foro provincial.

Por fin, otro aspecto que creemos interesante mencionar es la cercanía estilística del relieve de Agrippa con el llamado grupo de Eneas ${ }^{160}$ de este recinto superior forense. La calidad de los roléos del remate de la coraza de Eneas ${ }^{161}$ y la factura del mismo motivo del dorsuale del toro del relieve, son muy próximas: ¿Estamos ante el mismo taller? ¿Efectúa éste todo un denso programa de marmorización de un complejo precedente augusteo, ya trasnochado, poblado de granito estucado?

Hasta el presente, no se ha producido el afortunado hallazgo en Mérida de muestras arqueológicas de la existencia del altar, como en otras zonas del Imperio. Nuestra idea es plantear la necesidad de efectuar un riguroso trabajo de campo, dentro del programa del Foro al que nos vinculamos en el año 1979, que nos permita aclarar esta cuestión. Confiamos que nuestra hipótesis de trabajo se acepte por las instituciones responsables.

En otras zonas del Imperio, como Augusta Rauricorum, además de encontrarse las cimentaciones del altar en la fachada anterior del templo, se

\footnotetext{
Vid. bibliografía cit. supra.

W. Trillmich, art. cit. MM 36, 1995, págs. 269-291.

S. DE MARIA, Gli archi honorari di Roma e dell italia Romana. Roma, 1988.

DE LA BARRERA-TRILIMICH, art. cit. supra.

lbid. lám. 31, 2.
} 
han exhumado las placas decorativas con objetos rituales, patera y urceus, circundados por coronas de laurel ${ }^{162}$.

Templos y los altares se asocian constantemente ${ }^{163}$, no sólo en la capital del Imperio se produce esta duplicidad simbólica en el espacio sacro ${ }^{164}$, las provincias asumen con bastante rapidez este esquema, que se manifiesta en Camulodunum ${ }^{165}$ o el que nos ocupa de Augusta Emerita $^{166}$.

162 P. A. SchWARz, “Neue Erkennntnisse zumForums-Altar und Forums-Tempel in Augusta Rauricorum (Augst. BL). Die Ergebnisse der Grabung 1990. 54», JbAK 12, 1991, págs. 161-197, figs. 1, 2 y 4; C. BosSERT-RADTKE, «Neue und alte Marmofragmente des Augster Forums-Altarseine erste Zwischenbilanz zur Untersuchung von 1990», JbAK 12, 1991, págs. 199-209.

163 FISHWICK, ICLW I, 1, págs. 154 y ss, ICLW II, 1., págs. 519 y ss.

164 M. TORELLI, op. cit. passim.

165 FISHWICK, ICLW I, 2, págs. 195-218; Id., "The Temple of Divus Claudius at Camulodunum", Britannia XXVI, 1995, págs. 11-28.

166 FISHWICK, ICLW I, 1, págs. 180 y ss. vid. bibliografia más completa supra. 